Annales Geophysicae (2003) 21: 893-913 (c) European Geosciences Union 2003

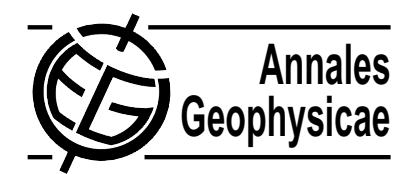

\title{
On the lifetime and extent of an auroral westward flow channel (AWFC) observed during a magnetospheric substorm
}

\author{
M. L. Parkinson ${ }^{1}$, M. Pinnock ${ }^{2}$, H. Ye ${ }^{3}$, M. R. Hairston ${ }^{4}$, J. C. Devlin ${ }^{3}$, P. L. Dyson ${ }^{1}$, R. J. Morris ${ }^{5}$, and \\ P. Ponomarenko 6 \\ ${ }^{1}$ Department of Physics, La Trobe University, Victoria 3086, Australia \\ ${ }^{2}$ British Antarctic Survey, Natural Environment Research Council, Cambridge CB3 OET, UK \\ ${ }^{3}$ Department of Electronic Engineering, La Trobe University, Victoria 3086, Australia \\ ${ }^{4}$ William B. Hanson Center for Space Sciences, University of Texas at Dallas, Richardson, Texas, USA \\ ${ }^{5}$ Australian Antarctic Division, Kingston, Tasmania 7050, Australia \\ ${ }^{6}$ Department of Physics, University of Newcastle, New South Wales 2038, Australia
}

Received: 6 May 2002 - Revised: 24 October 2002 - Accepted: 8 November 2002

\begin{abstract}
A -190 -nT negative bay in the geomagnetic $X$ component measured at Macquarie Island $\left(-65^{\circ} \Lambda\right)$ showed that an ionospheric substorm occurred during 09:58 to 11:10 UT on 27 February 2000. Signatures of an auroral westward flow channel (AWFC) were observed nearly simultaneously in the backscatter power, LOS Doppler velocity, and Doppler spectral width measured using the Tasman International Geospace Environment Radar (TIGER), a Southern Hemisphere HF SuperDARN radar. Many of the characteristics of the AWFC were similar to those occurring during a polarisation jet (PJ), or subauroral ion drift (SAID) event, and suggest that it may have been a precursor to a fully developed, intense westward flow channel satisfying all of the criteria defining a PJ/SAID. A beamswinging analysis showed that the westward drifts (poleward electric field) associated with the flow channel were very structured in time and space, but the smoothed velocities grew to $\sim 800 \mathrm{~m} \mathrm{~s}^{-1}\left(47 \mathrm{mV} \mathrm{m}^{-1}\right)$ during the 22-min substorm onset interval 09:56 to 10:18 UT. Maximum westward drifts of $>1.3 \mathrm{~km} \mathrm{~s}^{-1}\left(>77 \mathrm{mV} \mathrm{m}^{-1}\right)$ occurred during a $\sim 5$-min velocity spike, peaking at 10:40 UT during the expansion phase. The drifts decayed rapidly to $\sim 300 \mathrm{~m} \mathrm{~s}^{-1}$ $\left(18 \mathrm{mV} \mathrm{m}^{-1}\right)$ during the 6-min recovery phase interval, 11:04 to $11: 10 \mathrm{UT}$. Overall, the AWFC had a lifetime of $74 \mathrm{~min}$, and was located near $-65^{\circ} \Lambda$ in the evening sector west of the Harang discontinuity. The large westward drifts were confined to a geographic zonal channel of longitudinal extent $>20^{\circ}$ ( $>1.3 \mathrm{~h}$ magnetic local time), and latitudinal width $\sim 2^{\circ} \Lambda$. Using a half-width of $\sim 100 \mathrm{~km}$ in latitude, the peak electric potential was $>7.7 \mathrm{kV}$. However, a transient velocity of $>3.1 \mathrm{~km} \mathrm{~s}^{-1}$ with potential $>18.4 \mathrm{kV}$ was observed further poleward at the end of the recovery phase. Auroral oval boundaries determined using DMSP measurements suggest
\end{abstract}

Correspondence to: M. L. Parkinson

(m.parkinson@latrobe.edu.au) the main flow channel overlapped the equatorward boundary of the diffuse auroral oval. During the $\sim 2$-h interval following the flow channel, an $\sim 3^{\circ} \Lambda$ wide band of scatter was observed drifting slowly toward the west, with speeds gradually decaying to $\sim 50 \mathrm{~m} \mathrm{~s}^{-1}\left(3 \mathrm{mV} \mathrm{m}^{-1}\right)$. The scatter was observed extending past the Harang discontinuity, and had Doppler signatures characteristic of the main ionospheric trough, implicating the flow channel in the further depletion of F-region plasma. The character of this scatter was in contrast with the character of the scatter drifting toward the east at higher latitude.

Key words. Ionosphere (auroral ionosphere; electric fields and currents; ionosphere-magnetospehere interactions) Magnetospheric physics (storms and substorms)

\section{Introduction}

Transient $(\sim 1 \mathrm{~h})$, supersonic $\left(>1 \mathrm{~km} \mathrm{~s}^{-1}\right.$ ) westward flows of ionospheric plasma are sometimes observed confined within narrow latitudinal channels $\left(<2^{\circ}\right)$ just equatorward of, or overlapping, the equatorward edge of the diffuse auroral oval in the evening sector ( $\sim 22 \mathrm{~h}$ magnetic local time; MLT) (e.g. De Keyser, 1998). These events were originally called polarisation jets (PJs) by their discoverers, Galperin et al. (1973), but have also become known as subauroral ion drift events (SAIDs) (Spiro et al., 1979), despite the fact that SAIDs often overlap the diffuse auroral oval. Most observations of PJ/SAIDs have been made using instruments on board satellites (e.g. Smiddy et al., 1977; Rich et al., 1980; Anderson et al., 1991, 1993; Karlsson et al., 1998), but a few groundbased radar observations have also been reported (Galperin et al., 1986; Providakes et al., 1989; Yeh et al., 1991).

In this paper we report observations of an auroral westward flow channel (AWFC) observed at $~ 22: 00$ MLT and 
magnetic latitude $\sim-65^{\circ} \Lambda$ on 27 February 2000. Signatures of the event appeared in the backscatter power $(\mathrm{dB})$, line-of-sight (LOS) Doppler velocity $\left(\mathrm{m} \mathrm{s}^{-1}\right)$, and Doppler spectral width $\left(\mathrm{m} \mathrm{s}^{-1}\right)$ measured using the Tasman International Geospace Environment Radar (TIGER) (Dyson and Devlin, 2000), a Southern Hemisphere member of the Super Dual Auroral Radar Network (SuperDARN) (Greenwald et al., 1985, 1995). The behaviour of the AWFC resembled the behaviour of a relatively weak PJ/SAID, yet its growth and decay were synchronised with substorm onset and recovery, respectively. In this regard, the AWFC more closely resembled the substorm-associated radar auroral surges (SARAS) observed using VHF radar in the afternoon sector (Freeman et al., 1992).

This study reports HF radar observations of a class of relatively weak, subauroral westward flow channels that has apparently been excluded from previous satellite-based studies. The behaviour of AWFC, SARAS, and PJ/SAID needs to be understood in the context of other poorly understood substorm processes which have been investigated in numerous other studies. For example, a study by Sánchez et al. (1996) is especially relevant here because of its comprehensive synthesis of HF radar, magnetometer, and Defence Meteorological Satellite Program (DMSP) observations. Although we cannot be certain that our 27 February event was not driven by nightside reconnection, its persistent character and probable mapping to a region of closed field lines suggests that it was more closely related to PJ/SAIDs. To this end, we first review recent observations and theory pertaining to PJ/SAIDs.

\section{PJ/SAID review}

Anderson et al. (1991) studied PJ/SAIDs using Atmospheric Explorer $\mathrm{C}$ and Dynamics Explorer B spacecraft measurements. They defined PJ/SAIDs as having westward drifts of at least $1 \mathrm{~km} \mathrm{~s}^{-1}$, with velocities up to $4 \mathrm{~km} \mathrm{~s}^{-1}$ often occurring in the evening sector. However, weaker PJ/SAID-related drifts $<1 \mathrm{~km} \mathrm{~s}^{-1}$ must also occur, though with more structure (Karlsson et al., 1998). Anderson et al. (1993) observed flow channels with full-width half-maxima of $\sim 1^{\circ}$ in latitude, and estimated life times in the range $30 \mathrm{~min}$ to $3 \mathrm{~h}$, commencing during the substorm recovery phase. They did not observe any events within 30 min of substorm onset, but their results were not definitive due to intermittent satellite sampling. Karlsson et al. (1998) provided a comprehensive account of PJ/SAID occurrence statistics compiled using Freja satellite data.

Anderson et al. (1991) also observed large enhancements in the ionospheric ion temperature, upward vertical drift, and associated depletions in low-altitude ion density. These are the familiar consequences of ion-neutral friction foreseen by Schunk et al. (1975), and modelled by Sellek et al. (1991) and Heelis et al. (1993). The $\mathrm{O}^{+}$and $\mathrm{O}_{2}^{+}$recombination rates are elevated when the difference between the ion and neutral speeds is large. When the ion speed suddenly increases and persists for $\sim 10-15 \mathrm{~min}$, the frictional heating can lead to the formation of deep depletions in ionospheric plasma concentration. The frictional heating may also lead to the formation of a stable auroral red arc (Foster et al., 1994).

Anderson et al. (1991) reported PJ/SAIDs collocated with the poleward edge of the main ionospheric trough, leading to the formation of very deep depletions inside the preexisting trough, presumably formed by stagnation (e.g. Quegan et al., 1982; Sojka and Schunk, 1989; Rodger et al., 1992). These are the "troughs within troughs" reported by Galperin et al. (1986). Incoherent scatter radar observations show troughs are often narrow latitudinal features, only $\sim 1^{\circ}$ wide (Jones et al., 1997). PJ/SAIDs may also cause noticeable plasma depletions at plasmaspheric altitudes (Ober et al., 1997). Clearly, there is an intimate relationship between PJ/SAIDs, the formation of high-latitude troughs, the location of the plasmapause, and the structure within the highaltitude plasma trough.

Southwood (1977) gave a fluid description of the shielding of the low-latitude ionosphere from convection electric fields. During a geomagnetic storm, the dawn-to-dusk electric field causes an earthward drift of plasma in the magnetotail. If unimpeded, this would map to purely sunward flows migrating all the way down to the equatorial ionosphere. However, the earthward-drifting plasma clouds encounter radial pressure gradients approaching the inner edge of the ring current (near the plasmapause), whereupon eastwest gradients in plasma pressure grow. These gradients divert the plasma flow in the zonal direction, thereby shielding the plasmasphere (mid-latitude ionosphere) from the crosstail electric field. In the co-rotating frame, these zonal drifts are slowly toward the east post-midnight, but strongly toward the west pre-midnight.

Southwood (1977) suggested the hot plasma pressure, its number density in the inner nightside magnetosphere, and the ionospheric conductivity are the key parameters controlling the penetration of convection electric field to low latitude. This is because the magnetospheric convection will tend to avoid expending energy in plasma compression and Joule heating (Cole, 1962) in magnetically connected regions of large ionospheric conductivity (Axford, 1969). These ideas suggest that PJ/SAIDs will inevitably manifest in the ionospheric region mapping to just outside the sharp pressure gradients located near the plasmapause, yet just equatorward of the highly conducting auroral zone. PJ/SAIDs will persist until there is no longer an equilibrium between the coupled magnetosphere-ionosphere forces generating the polarisation field, and the shorting out of this field by field-aligned currents closing via ionospheric Pedersen currents (and the associated Joule heating).

Any PJ/SAID theory must explain the formation of an intense, spatially localised polarisation field directed poleward in the ionosphere, and radially in the inner magnetosphere. Invoking a magnetospheric driver, there must be a radial separation of the ion and electron ring currents, with more ions located closer to Earth. Anderson et al. (1993) suggested that PJ/SAID do not form at the time of substorm onset be- 


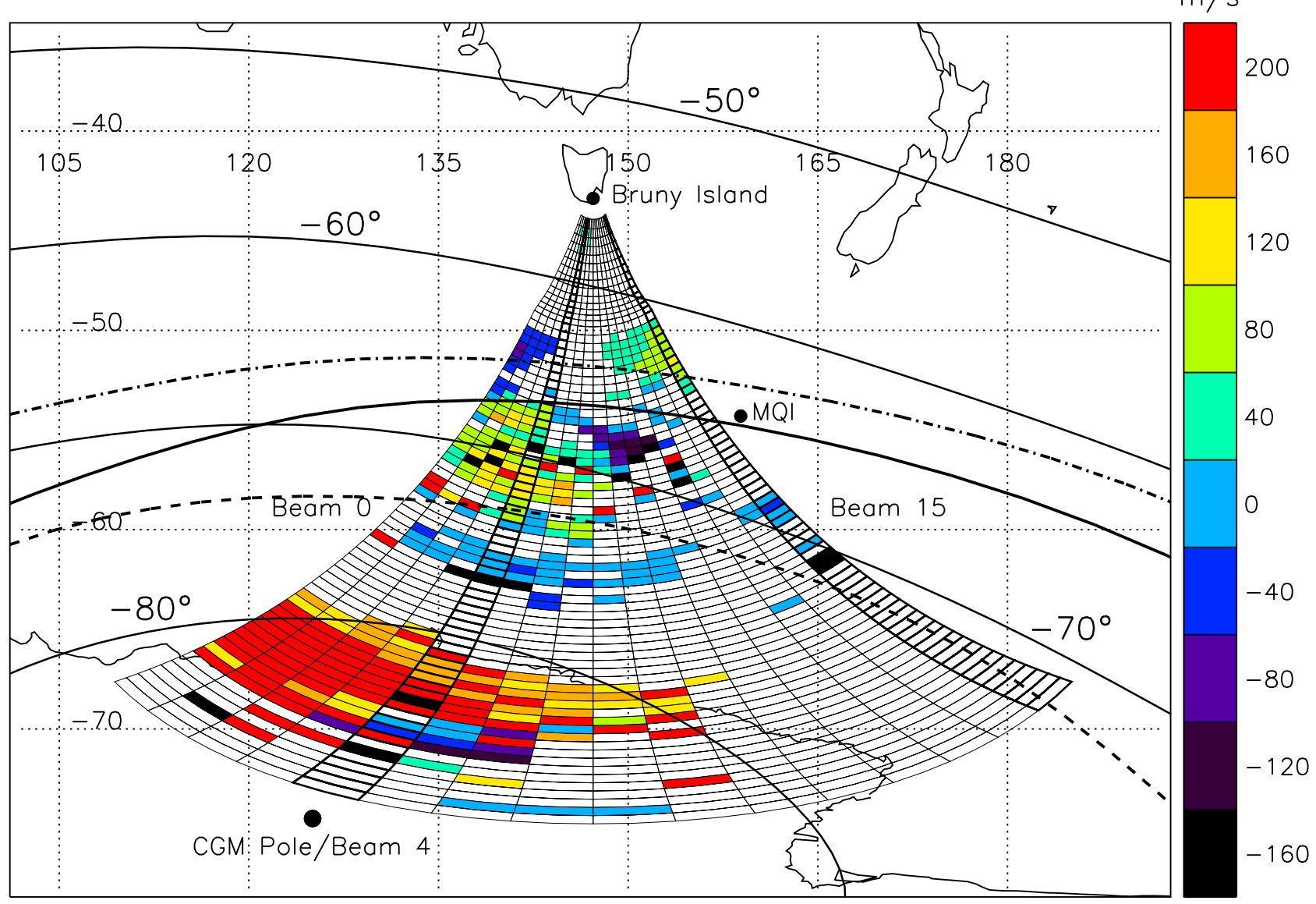

Fig. 1. Field of view (FOV) of the TIGER radar mapped to cylindrical geographic coordinates with AACGM latitudes $-50^{\circ},-60^{\circ},-70^{\circ}$, and $-80^{\circ} \Lambda$ superimposed. Beam 4 , which points toward the CGM pole, and beam 15 , which becomes a magnetic zonal beam at the furthest ranges, are shown in bold. LOS Doppler velocities recorded during the full scan commencing at 12:34 UT on 27 February 2000 are also shown. The colour key means that all velocities in the range $140<v_{\mathrm{LOS}} \leq 180 \mathrm{~m} \mathrm{~s}^{-1}$ are coloured orange. Auroral oval boundaries given by the Starkov (1994) model for $A L=-150 \mathrm{nT}$ and Macquarie Island (MQI) located at 22:00 MLT have been superimposed: poleward boundary of discrete aurora (dashed curve), the equatorward boundary of discrete aurora (solid curve), and the equatorward boundary of diffuse aurora (dashed-dotted curve).

cause ion and electron precipitation share a common, dispersionless, equatorward boundary (Newell and Meng, 1987). Thereafter, the inner edges of the ion and electron plasma sheets separate on a time scale of $\sim 10 \mathrm{~min}$, with the hot ions moving further earthward than the hot electrons in the evening sector as the Alfvén layer forms (Kivelson and Russel, 1995). This leads to the formation of an initial radial polarisation field. Since the hot ions are injected near midnight first, and then drift westward in the ring current, we might also expect the ionospheric signature of PJ/SAIDs to expand westward from the Harang discontinuity.

Anderson et al. (1993) also emphasised the importance of ion-neutral frictional heating in the ionosphere, leading to a reduction in plasma density and thus conductivity. As long as the magnetospheric driver supplies the same fieldaligned current closing via Pedersen current in the ionosphere $\left(J_{p}=\Sigma_{p} E\right)$, a runaway effect develops: the electric field, $E$, increases, leading to a further decrease in heightintegrated conductance, $\Sigma_{p}$, leading to a further increase in the electric field, etc. Hence, narrow, westward drifts may rapidly grow to $>4 \mathrm{~km} \mathrm{~s}^{-1}$ at subauroral latitudes during substorms.

De Keyser (1999) argued the space-charge layer associated with the Alfvén layer is too thick to explain the narrow latitudinal width of PJ/SAIDs. He proposed that an intense radial electric field is generated by a thermoelectric effect, namely a strong temperature gradient develops across the interface between cold, plasma trough plasma ( $T_{\text {electrons }} \approx$ $0.75 \mathrm{eV} ; T_{\text {protons }} \approx 1.5 \mathrm{eV}$ ) and hot, plasma sheet plasma $\left(T_{\text {electrons }} \approx 1 \mathrm{keV} ; T_{\text {protons }} \approx 10 \mathrm{keV}\right)$, the latter injected at substorm onset. Space-charge separation develops because the various particles with different energies have different gyroradii. The azimuthal flow shear between the partially corotating plasma near the plasmapause and the newly injected plasma must also be considered: the hot plasma drifts westward pre-midnight and eastward post-midnight. Hence, the flow-shear electric field reinforces the thermoelectric field in the evening sector, but suppresses it in the morning sector. 
This explains the strong preference for PJ/SAIDs to occur in the evening sector.

The semi-quantitative model of PJ/SAIDs recently proposed by Galperin (2002) considers the distribution functions of ion and electron energies injected into the ring current region. Galperin (2002) argued that (1) the formation time of a PJ/SAID will be $\sim 5-10 \mathrm{~min}$, (2) the initial injection will be near the tip of the Harang discontinuity, which will be displaced by several hundred $\mathrm{km}$, (3) the latitudinal profile of enhanced poleward electric field will be bell-shaped with a width of $\sim 100 \mathrm{~km}\left(\sim 1^{\circ}\right)$, (4) an electric potential of $\sim 10 \mathrm{kV}$ will map over the same distance, (5) the Pedersen conductance $\Sigma_{p}$ will be $\sim 0.1 \mathrm{~S}$ (versus $\sim 10 \mathrm{~S}$ in the auroral oval) and a height-integrated Pedersen current density $\sim 10^{-2} \mathrm{~A} \mathrm{~m}^{-1}$ will flow across the PJ, (6) the lifetime of the PJ/SAID will be $\sim 1-3 \mathrm{~h}$, and (7) the PJ/SAID will extend for at least $3 \mathrm{~h}$ in MLT. This recipe for a PJ/SAID agrees with numerous satellite observations, but needs further testing.

Spacecraft observations have provided important insights into the spatial extent and timing of PJ/SAIDs relative to substorm processes. Satellites have obtained high-time resolution measurements of PJ/SAID processes along single orbits traversing the events. However, due to the typical orbital period of $\sim 90 \mathrm{~min}$ for satellites in the topside ionosphere, the effective time resolution and spatial coverage is poor when a satellite encounters the same event during a subsequent orbit. No doubt this problem will be addressed in future experiments deploying large clusters of "nano-satellites". Meanwhile, ground-based HF backscatter radar observations offer an excellent opportunity to image PJ/SAID processes occurring almost continuously in space and time.

In this paper, we report comprehensive observations of an AWFC made using a HF radar supported by coincident spacecraft measurements. By an AWFC we simply mean a PJ/SAID-like event with well above average westward drifts overlapping or residing within the auroral oval and possibly synchronised to substorm dynamics. We suggest that AWFC, SARAS, and PJ/SAIDs are governed by closely-related electrodynamic processes occurring during substorms.

\section{Observations and interpretation}

TIGER (Dyson and Devlin, 2000) is a SuperDARN radar (Greenwald et al., 1985, 1995) located on Bruny Island (43.4 ${ }^{\circ} \mathrm{S}, 147.2^{\circ} \mathrm{E}$ geographic), Tasmania (Fig. 1). Under routine operation, TIGER performs one sequential 16-beam scan from east (beam 15) to west (beam 0), integrating for $7 \mathrm{~s}$ on each beam. Hence, a full scan takes $112 \mathrm{~s}$, but successive scans are synchronised to the start of 2-min boundaries. The individual beams are separated by $3.24^{\circ}$, so the full scan is $52^{\circ}$ wide (though decreasing slightly with increasing frequency). The radar samples 75 different ranges separated by $45 \mathrm{~km}$ between 180 and $3555 \mathrm{~km}$. In practise, the radar detects useful ionospheric scatter from a fraction of the field of view (FOV) during a single scan. Nonetheless, the radar potentially detects scatter from $\sim 10^{6} \mathrm{~km}^{2}$ of the ionosphere every 2 min.

Figure 1 shows that TIGER beam 4 observation cells extend from magnetic latitude $-57^{\circ} \Lambda$ to $-88^{\circ} \Lambda$, which is $\sim 5^{\circ} \Lambda$ equatorward of the high-latitude ionosphere imaged by most SuperDARN radars. Hence, TIGER's location is optimum for the study of substorm-related processes in the nightside ionosphere during quiet and moderate geomagnetic activity. Here we report routine HF radar observations of an AWFC located at $\sim-65^{\circ} \Lambda$, and commencing at 09:56 UT (22:00 MLT) on the evening of 27 February 2000. The observations were made using the routine, 2-min full-scan sounding mode, as previously described.

The line-of-sight (LOS) Doppler velocities $\left(\mathrm{m} \mathrm{s}^{-1}\right)\left(v_{\mathrm{LOS}}\right)$ recorded during the 112-s interval commencing at 12:34 UT on 27 February, 2000 have been superimposed in Fig. 1. Note the absence of near-range scatter on beams 4 to 8 . As will be discussed, the ionospheric irregularities drifted slowly $\left(<100 \mathrm{~m} \mathrm{~s}^{-1}\right)$ toward the west equatorward of $\sim-66^{\circ} \Lambda$, and were probably associated with the main ionospheric trough. Immediately poleward, the irregularities drifted with moderate speed $\left(>100 \mathrm{~m} \mathrm{~s}^{-1}\right)$ toward the east, thereby delineating the location of the flow reversal boundary (FRB) (Huang et al., 2001). The AWFC preceded this observation and was part of the process forming the FRB near the equatorward edge of the auroral oval.

We relate our TIGER observations to the timing of auroral substorms inferred from magnetometer observations made at nearby Macquarie Island (MQI) $\left(54.5^{\circ} \mathrm{S}, 158.9^{\circ} \mathrm{E}\right.$; $-65^{\circ} \Lambda$ ). Interpretation of the observations was supported by coincident Wind and Interplanetary Monitoring Platform 8 (IMP 8) solar wind measurements, Defence Meteorological Satellite Program (DMSP) precipitation measurements, Los Alamos National Laboratory (LAN-L) geosynchronous $\left(6.6 R_{E}\right)$ spacecraft measurements of energetic particle fluxes, ionosonde measurements made at MQI, and total electron content (TEC) measurements made at MQI and Hobart $\left(42.9^{\circ} \mathrm{S}, 147.3^{\circ} \mathrm{E} ;-54^{\circ} \Lambda\right)$.

\subsection{Solar wind observations}

At 10:00 UT on 27 February 2000, the IMP 8 spacecraft was located below the equatorial plane on the dusk flank of the magnetosphere at geocentric solar magnetospheric (GSM) $x$, $y$, and $z$ coordinates of $-2.7,36.5$, and $-18.8 R_{E}$, respectively. Figure 2 shows IMP 8 measurements (bold lines with solid dots) of the interplanetary magnetic field (IMF) components in GSM coordinates (parts a-c), and simultaneous measurements of the solar wind dynamic pressure (part d). There were substantial outages in measurements made with the ageing IMP 8, so continuous Wind spacecraft measurements of the same parameters are included (faint curves). At 10:00 UT, the Wind spacecraft was located much further upstream in the solar wind at GSM coordinates $(173.9,30.3$, $17.4 R_{E}$ ). The Wind measurements were advanced in time by $33.5 \mathrm{~min}$ to allow for advection of the IMF conditions from Wind to IMP 8 at a representative solar wind speed of 


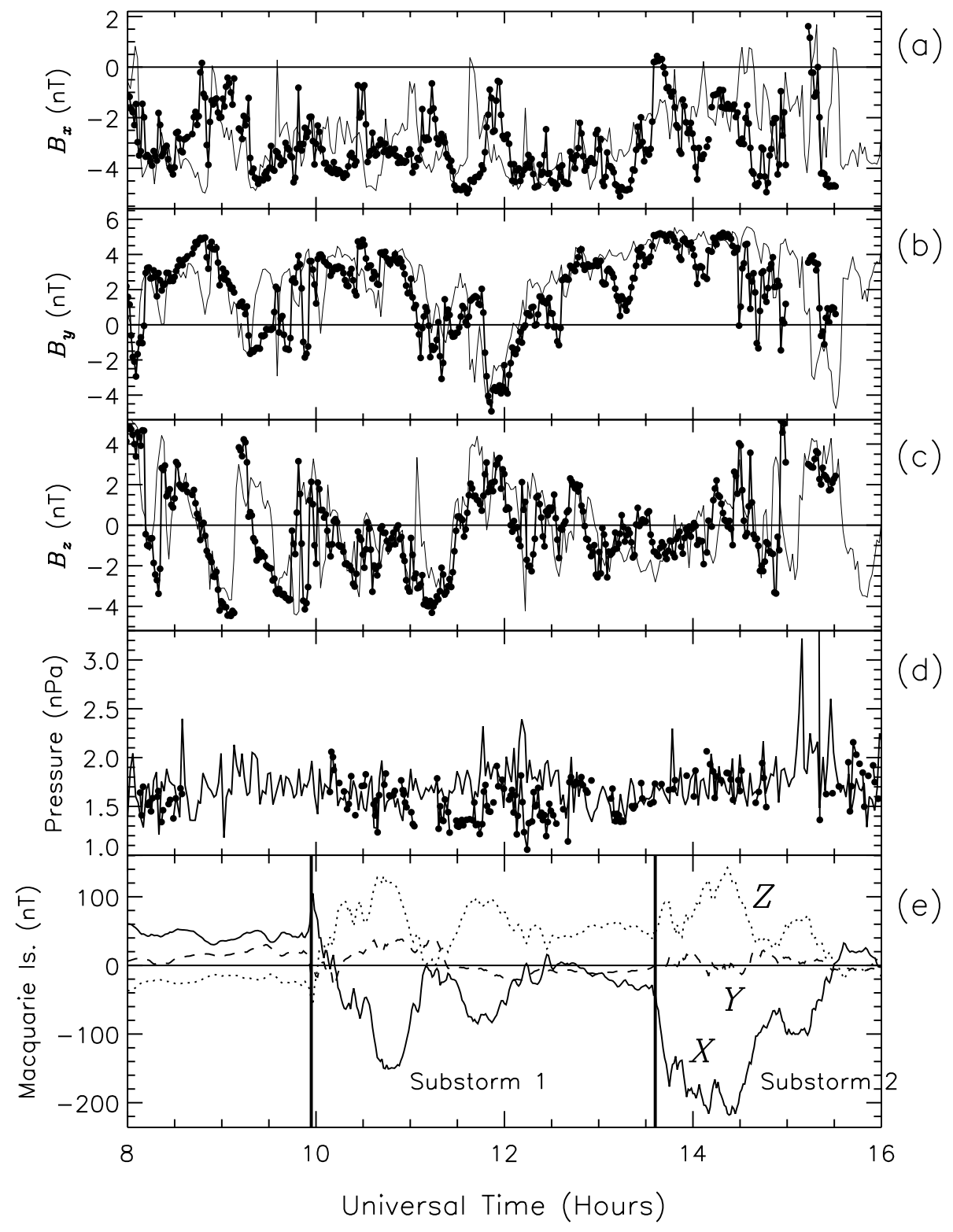

Fig. 2. IMP 8 spacecraft measurements (bold lines with solid dots) of the IMF (a) $B_{x}$, (b) $B_{y}$, and (c) $B_{z}$ components made at $\sim 1$-min time resolution, and (d) the solar wind dynamic pressure during 08:00 to 16:00 UT on 27 February 2000. The corresponding Wind spacecraft measurements made at $\sim 1.5$-min time resolution for the same period, except advanced by 33.5 min to allow for advection of the solar wind to the location of IMP 8, are superimposed as faint curves. (e) Perturbations of the geomagnetic $X$ (solid curve), $Y$ (dashed curve), and $Z$ (dotted curve) components measured by the MQI magnetometer (data provided courtesy of the Australian Geological Survey Organisation). The abscissas have tick marks at 30-min intervals of UT.

$560 \mathrm{~km} \mathrm{~s}^{-1}$. To reduce clutter in the plot, ACE spacecraft measurements are not shown.

The IMP 8 and Wind IMF measurements agreed in the basic trends occurring on time scales $>15 \mathrm{~min}$, but there were many differences occurring on shorter time scales. These were partly caused by instrumental errors, evolution of the solar wind, and by discontinuities and waves propagating at much higher speed within the background flow. Clearly, a spacecraft with reliable instruments deployed nearby the Earth's magnetosphere provides the best indication of geoeffective solar wind conditions. In summary:
1. The IMF $B_{x}$ component was continuously fluctuating, mostly in the range -1 to $-5 \mathrm{nT}$.

2. $B_{y}$ was predominately positive in the range 2 to $5 \mathrm{nT}$, but with significant negative excursions during 09:17 to 09:55 UT, and especially 11:04 to $12: 13$ UT.

3. $B_{z}$ was predominately negative in the range -1 to $-4.5 \mathrm{nT}$, but with many northward excursions, too numerous to warrant separate listing. 
4. Excluding continuous short-term fluctuations, the solarwind dynamic pressure was reasonably steady at around $1.7 \mathrm{nPa}$. However, significant changes in pressure $(\sim 35 \%)$ occurred at 11:46 and 12:11 UT, and large pressure pulses ( $>88 \%)$ occurred at 15:09 and 15:20 UT.

\subsection{Ground-based magnetometer observations}

Macquarie Island (MQI) $\left(-65^{\circ} \Lambda\right)$ is located just east of TIGER beam 15 , having the same magnetic latitude as range cell $26(1350 \mathrm{~km})$ (Fig. 1). Figure 2e shows MQI magnetometer perturbations in the geomagnetic $X$ (north), $Y$ (east), and $Z$ (down) components. These measurements were despiked and then detrended by subtracting a baseline defined by their average diurnal values. The two largest negative bays in the $X$ component exhibited the classic signatures of ionospheric substorms. We have labelled them "Substorm 1" and "Substorm 2," but lesser intensifications occurred, just after both substorms.

Substorm 1 was not preceded by an obvious growth-phase signature (McPherron, 1970). Rather, its onset was marked by an $\sim 60$-nT impulsive increase in the $X$ component, starting at 09:53 UT, and peaking at 09:58 UT (bold vertical line). This feature was reminiscent of storm sudden commencement (ssc), a feature normally observed in dayside magnetograms when magnetopause currents are enhanced by magnetospheric compression (Kelley, 1989). However, the behaviour of the IMF $B_{z}$ component does not suggest unusually enhanced dayside reconnection; nor was there a significant dynamic pressure pulse at this time. Hence, the feature suggests a strong, short-lived current flowing toward the east, opposite to the ring current. We will argue this feature was a signature of an emerging AWFC.

Substorm 1 was possibly triggered by $B_{z}$ swinging northward after a preceding succession of $B_{z}$ southward turnings (Fig. 2c). We expect a very short delay for the ionosphere to respond to IMF conditions measured at GSM $x=-2.7 R_{E}$. There were several intensifications in the $X$ component during the onset and expansion phase, reaching a maximum deflection of $-190 \mathrm{nT}$ relative to our pre-storm baseline. The recovery phase commenced at 10:53 UT, and finished at 11:10 UT. A lesser intensification to $-83 \mathrm{nT}$ began near 11:28 UT, and was possibly driven by a lesser $B_{z}$ southward turning.

Substorm 2 had stronger Hall current flow than Substorm 1. The growth-phase signature in the $X$ component began at 12:43 UT, if not earlier, possibly in response to $B_{z}$ trending weakly southward yet again. Expansion onset was at 13:36 UT (bold vertical line), and the main phase subsequently deepened to $-218 \mathrm{nT}$. The recovery phase commenced at 14:27 UT, and finished at 15:37 UT. A final, lesser intensification to $-100 \mathrm{nT}$ began at 14:55 UT.

Deflections in the $Y$ component were relatively small throughout the study interval, in agreement with the essentially zonal alignment of the familiar westward electrojet. The large negative deflections in the $X$ component, and weaker positive deflections in the $Z$ component, imply the ionospheric Hall current flowed strongly westward, but centred several hundred kilometres poleward of the station. Reinterpreted as F-region drifts, this implies the plasma was convecting strongly toward the east.

Preliminary $A E$ indices calculated during this event behaved similar to the MQI magnetometer deflections (Fig. 2e), except that the amplitudes of the $A E$ indices were much greater, reaching $507 \mathrm{nT}$ at 10:07 UT. No doubt this was because the Northern Hemisphere magnetometer locations were spread in longitude, thereby providing comprehensive coverage of conjugate current flow. Finally, the provisional $D_{s t}$ index for 10:00 UT on 27 February was only $-1 \mathrm{nT}$, and $K_{p}$ was 3 during the three-hour interval commencing at 09:00 UT.

\subsection{Geosynchronous satellite observations}

The LAN-L series of geosynchronous satellites measure the spin-averaged differential fluxes (particles $\mathrm{cm}^{-2} \mathrm{~s}^{-1} \mathrm{sr}^{-1} \mathrm{keV}^{-1}$ ) of energetic electrons and protons in the energy ranges $50 \mathrm{keV}$ to $26 \mathrm{MeV}$ and $>50 \mathrm{keV}$, respectively. When dispersionless particle injections are observed they indicate the initial longitude of substorm onset (Henderson et al., 1996). LAN-L 1989-046 was located at 22:53 MLT when it observed the start of a dispersionless particle injection at 09:58 UT on 27 February 2000. This was the same time as the peak of an impulsive increase in the $X$ component measured by the MQI magnetometer at the start of Substorm 1 (Fig. 2e). The flux of geosynchronous protons showed a distinct peak at 10:08 UT, and was greater than the electron flux which grew more gradually. We speculate this indicates the greater earthward penetration of hot protons, and the subsequent development of a radial polarisation field corresponding to an AWFC in the ionosphere.

LAN-L 1989-046 was located at 02:29 MLT when it observed the start of step-like intensifications in electron fluxes at 13:38 and 13:59 UT. LAN-L 1994-084 was located at 20:35 MLT when it observed the start of impulsive increases in energetic proton fluxes at 13:54 UT. When allowing for the relative MLTs of the spacecraft, these times can be reconciled with 13:36 UT, our estimate of the onset of Substorm 2 using the MQI magnetometer data.

\subsection{TIGER HF radar and DMSP observations}

Figure 3 shows range-time-intensity (RTI) plots of (a) the backscatter power (dB), (b) LOS Doppler velocity $\left(\mathrm{m} \mathrm{s}^{-1}\right)$, and (c) Doppler spectral width $\left(\mathrm{m} \mathrm{s}^{-1}\right)$ measured on TIGER beam 15 during 09:00 to 14:00 UT on 27 February 2000. The three parameters were calculated using the standard "FITACF" algorithm (Baker et al., 1995) used to process all SuperDARN autocorrelation measurements. Each pixel represents a parameter estimated using a 7-s integration time repeated once every two minutes, and sampled at $45-\mathrm{km}$ steps in range. Any echoes FITACF identified as coming from the sea were rejected in this study. The two thin, black horizontal lines in all panels represent magnetic latitudes 


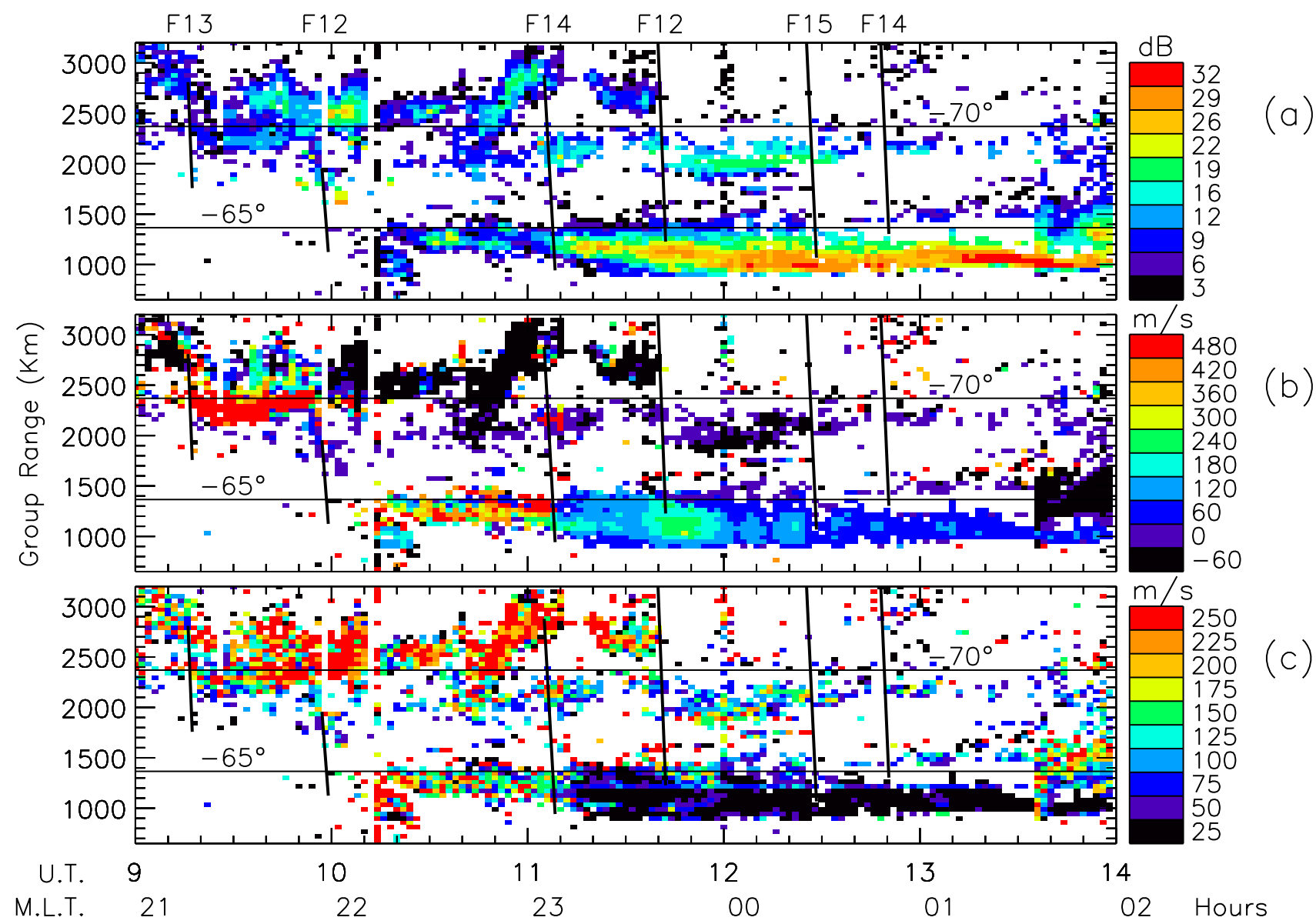

Fig. 3. RTI plots of (a) TIGER backscatter power (dB), (b) LOS Doppler velocity $\left(\mathrm{m} \mathrm{s}^{-1}\right)$, and (c) spectral width ( $\left.\mathrm{m} \mathrm{s}^{-1}\right)$ measured every 2 min on the eastward-looking beam 15 during 09:00 to 14:00 UT on 27 February 2000. Note the colour scale for LOS Doppler velocity is shifted towards large approaching values (i.e. strong azimuthal flows toward the west). The two thin, black, horizontal lines in all panels correspond to magnetic latitudes of $-65^{\circ}$ (MQI) and $-70^{\circ} \Lambda$. The six diagonal line segments in all panels represent the location of the discrete and diffuse auroral ovals identified along "nearby" transits (see text) of the DMSP F12, F13, F14, and F15 satellites, as labelled. The abscissas have tick marks at 10-min intervals of UT, but nominal values of MLT above MQI are also given.

of $-65^{\circ} \Lambda$ (MQI) and $-70^{\circ} \Lambda$, calculated using altitude adjusted corrected geomagnetic coordinates (AACGM) (Baker and Wing, 1989).

Beam 15 is the most eastward and magnetic zonal-looking beam of the TIGER radar, reaching a maximum poleward latitude of $-71.8^{\circ} \Lambda$ (range cell 68) before folding back towards the equator beyond this range (Fig. 1). Magnetic latitude increases steadily at the closest ranges, but at the furthest ranges it increases asymptotically toward $-71.8^{\circ} \Lambda$. Beam 15 also traverses a substantial range of magnetic longitude. The nominal MLTs quoted here are for MQI, located nearby the range cells where many of the interesting ionospheric echoes were observed. Beam 15 observations were chosen for display because they provide the most detailed profile of the subauroral ionosphere imaged by TIGER, while also being especially sensitive to zonal flows confined within narrow channels. They are also the best observations for comparison with MQI ground-based measurements.

The DMSP series of spacecraft are near polar orbit- ing, Sun-synchronous satellites. They have an altitude of $830 \mathrm{~km}$ and an orbital period of $101 \mathrm{~min}$. The SS J/4 detectors (Hardy et al., 1984) measure precipitating ions and electrons from which spectra of differential energy flux $\left(\mathrm{eV} \mathrm{cm}^{-2} \mathrm{~s}^{-1} \mathrm{ster}^{-1} \mathrm{eV}^{-1}\right)$ are calculated every second. The spectra span the energy range $30 \mathrm{eV}$ to $30 \mathrm{keV}$. The magnetic coordinates of the satellite track are calculated using Tsyganenko's (1990) magnetic field lines (see Tsyganenko and Stern, 1996, and references therein) passing through the satellite down to an ionospheric footprint at an altitude $110 \mathrm{~km}$. The difference in magnetic latitudes of points located at altitudes of $110 \mathrm{~km}$ and $300 \mathrm{~km}$ are usually $<0.1^{\circ}$ for TIGER observation cells. In this paper we make use of nightside auroral oval boundaries automatically identified in DMSP energy spectra using the logical criteria outlined by Newell et al. (1996).

Table 1 is a summary of automatically identified boundaries specifying the latitudinal extent of the diffuse and discrete auroral oval in the nightside ionosphere. The corre- 
Table 1. Nightside auroral oval boundaries superimposed in Figs. 3 and 4

\begin{tabular}{cccccc}
\hline DMSP & UT & Geographic Longitude & MLT (Hours) & Magnetic Latitude & Boundary \\
\hline F13 & 091607 & $145.9^{\circ}$ & 19.8 & $-71.1^{\circ}$ & $\mathrm{b} 5 \mathrm{e}$ \\
& 091723 & $143.4^{\circ}$ & 19.4 & $-67.3^{\circ}$ & $\mathrm{b} 1 \mathrm{i}$ \\
F12 & 095704 & $175.8^{\circ}$ & 23.3 & $-68.3^{\circ}$ & $\mathrm{b} 5 \mathrm{e}$ \\
& 095901 & $171.6^{\circ}$ & 22.6 & $-63.4^{\circ}$ & $\mathrm{b} 1 \mathrm{i}$ \\
F14 & 110504 & $162.5^{\circ}$ & 23.5 & $-71.2^{\circ}$ & $\mathrm{b} 5 \mathrm{e}$ \\
& 110824 & $155.9^{\circ}$ & 22.2 & $-62.1^{\circ}$ & $\mathrm{b} 1 \mathrm{i}$ \\
F12 & 113944 & $148.6^{\circ}$ & 22.6 & $-71.6^{\circ}$ & $\mathrm{b} 5 \mathrm{e}$ \\
& 114212 & $144.1^{\circ}$ & 21.8 & $-64.1^{\circ}$ & $\mathrm{b} 1 \mathrm{i}$ \\
F15 & 122509 & $149.5^{\circ}$ & 23.5 & $-72.3^{\circ}$ & $\mathrm{b} 5 \mathrm{e}$ \\
& 122830 & $143.6^{\circ}$ & 23.5 & $-63.0^{\circ}$ & $\mathrm{b} 1 \mathrm{e}$ \\
F14 & 124752 & $135.0^{\circ}$ & 22.3 & $-73.1^{\circ}$ & $\mathrm{b} 5 \mathrm{e}$ \\
& 125029 & $130.2^{\circ}$ & 21.6 & $-64.6^{\circ}$ & $\mathrm{b} 1 \mathrm{i}$ \\
\hline
\end{tabular}

sponding locations of the auroral oval are superimposed as diagonal, black lines drawn in all panels of Fig. 3. The boundaries were chosen using the most equatorward and poleward ion or electron boundaries available, which tended to be "b1i", the zero-energy ion boundary at the equatorward edge of the proton aurora, and "b5e", the abrupt drop in electron precipitation at the poleward edge. The individual dynamic spectra are not shown for brevity, but it is important to consult them to fully understand the unique particle dynamics involved during every transit of the auroral oval.

Unfortunately, the satellite tracks were not always closely aligned with the longitude of TIGER beam 15 , nor the longitude of any other beam containing interesting scatter (i.e. $\sim 140^{\circ}$ to $155^{\circ}$ geographic at $-65^{\circ} \Lambda$ ). The first transits of the F12 and F14 spacecraft were $\sim 1.8 \mathrm{~h}$ and $\sim 0.8 \mathrm{~h}$ to the east of the TIGER full scan, respectively. The auroral oval boundaries were probably located $1-2^{\circ}$ further poleward in the TIGER FOV due to the familiar equatorward expansion of the oval toward midnight. The second transit of the F14 spacecraft was $\sim 1.0 \mathrm{~h}$ to the west, implying that the auroral oval boundaries were located $\sim 1^{\circ}$ further equatorward in the TIGER FOV. The remaining transits were more favourably located. Given the substorms occurring during this evening, zonal perturbations in the auroral oval boundaries were inevitably larger than the familiar statistical variation with MLT. Nevertheless, the DMSP boundaries can be compared with the TIGER observations, keeping in mind that the discrepancies due to zonal structure were $<2^{\circ}$.

Figure 3 a reveals that there was patchy scatter poleward of $-66^{\circ} \Lambda$ with a moderate signal-to-noise ratio (SNR), mostly in the range 3 to $<20 \mathrm{~dB}$ (black to green). This scatter was associated with the auroral oval (thick diagonal lines) and polar cap ionosphere. The location of the latter is implied because the poleward edge of the auroral oval is a reasonable proxy for the open-closed magnetic field line boundary (OCB) (Vampola, 1971; Evans and Stone, 1972). Commencing at 10:12 UT, a persistent band of scatter $\sim 2^{\circ} \Lambda$ wide appeared at $\sim-64^{\circ} \Lambda$. Initially, the SNR was moderate, mostly $<20 \mathrm{~dB}$ (black to green), but at about 11:08 UT, the SNR grew to $>20 \mathrm{~dB}$ (green), and eventually peaked at $\sim 40 \mathrm{~dB}$ (red) near 13:35 UT. The band of scatter also expanded in width to $\sim 3^{\circ} \Lambda$ during 11:00 UT. The DMSP boundaries suggest that this scatter overlapped the equatorward edge of the auroral oval.

Figure $3 \mathrm{~b}$ shows the auroral and polar cap scatter located poleward of $-66^{\circ} \Lambda$ had mostly weak receding LOS Doppler velocity, $v_{\text {LOS }}$ (dark blue to black) after $\sim 09: 56$ UT. This meant that the true motion must have had a significant eastward component (recall beam 15 points towards the east). Consulting a two-cell convection model of the high-latitude ionosphere, such as the DMSP-based Ionospheric Convection Model (DICM) (Papitashvili and Rich, 2002), suggests that beam 15 should have been nearly orthogonal to flows exiting the polar cap and veering toward the east at 10:00 UT. However, the sign of the Doppler shift should have been very sensitive to fluctuations in the flow direction of plasma exiting the polar cap in proximity to the Harang discontinuity. The observed Doppler shifts were basically consistent with the expected convection velocities.

Figure $3 \mathrm{~b}$ also shows that during 09:15 to 09:56 UT at $\sim-69^{\circ} \Lambda$, there was a burst in $v_{\text {LOS }}$ toward the radar at $\sim 500 \mathrm{~m} \mathrm{~s}^{-1}$ (red). This flow burst immediately preceded the positive deflection in the MQI geomagnetic $X$ component (Fig. 2e), marking the onset of Substorm 1. The flow burst may have been a DP 2 current signature occurring simultaneously with the 8 -nT southward turning of $B_{z}$ (i.e. driven by dayside reconnection). Alternatively, it may have been the signature of weak nightside reconnection preceding the substorm (e.g. see Watanabe et al., 1998). Did the latter relieve the accumulation of open flux in the magnetotail, and help to explain the absence of a clear growth-phase signature in the MQI magnetometer observations?

Figure $3 \mathrm{~b}$ also shows that an AWFC occurred during 10:12 to 11:08 UT. The persistent band of scatter at $\sim-64^{\circ} \Lambda$ had large approaching LOS Doppler velocities up to $500 \mathrm{~m} \mathrm{~s}^{-1}$ (blue to red). Since beam 15 points more toward the pole than the east at these closer ranges, $v_{\text {LOS }} \approx 500 \mathrm{~ms}^{-1}$ implies true zonal flows $>1 \mathrm{~km} \mathrm{~s}^{-1}$. Close examination of Fig. $3 \mathrm{~b}$ 
reveals the presence of thin, red regions, only one range cell wide $(45 \mathrm{~km})$, implying the formation of small-scale flow transients, probably $<1^{\circ} \Lambda$ wide. The character of the pixels fluctuates in range and time, suggesting the presence of small-scale dynamics inaccessible using the existing radar gain, angular and temporal resolution. At 11:08 UT there was a step-like decrease in $v_{\mathrm{LOS}}$ to $\sim 100 \mathrm{~m} \mathrm{~s}^{-1}$ (blue) approaching the radar. Though perhaps a coincidence, the step-like decrease in $v_{\text {LOS }}$ was coincident with another $B_{z}$ southward turning. Figure $3 \mathrm{a}$ also shows a transition to larger power at 11:08 UT. The lower velocities in the flow channel persisted until the end of the record.

Figure $3 \mathrm{c}$ shows that during 09:00 to 11:40 UT, the spectral widths located in the polar cap ionosphere were generally large $\left(>200 \mathrm{~m} \mathrm{~s}^{-1}\right.$; red), whereas the sparse scatter associated with the discrete and diffuse auroral ovals had moderate spectral widths (50-150 $\mathrm{m} \mathrm{s}^{-1}$; blue and green). Nevertheless, there was a reasonably sharp transition to large spectral widths at the poleward edge of the auroral oval (the OCB), during this disturbed interval. Although some large spectral widths were observed equatorward of the OCB during 27 February, these data suggest the nightside spectral width boundary was a proxy for the OCB (see Parkinson et al., 2002).

Figure $3 \mathrm{c}$ also shows that during 10:12 to 11:08 UT, the persistent band of scatter at $\sim-64^{\circ} \Lambda$ had moderate to large spectral widths (100-250 $\mathrm{m} \mathrm{s}^{-1}$; blue to red). As will be shown later, the initial 10-min interval of large spectral widths $\left(>200 \mathrm{~m} \mathrm{~s}^{-1}\right)$ may have been associated with a familiar burst of Pi2 wave activity occurring at substorm onset (Saito, 1969). André et al. $(1999,2000)$ have argued that enhanced spectral widths observed by SuperDARN radars can be explained by the Doppler spread driven by Pc1-2 hydrodynamic wave activity. Perhaps broad-band ULF waves responsible for the large spectral widths are largely confined to the polar cap ionosphere during geomagnetically quiet conditions, whereas related waves are excited on closed field lines during disturbed intervals.

At 11:08 UT there was a step-like decrease in the spectral widths to values $<60 \mathrm{~m} \mathrm{~s}^{-1}$ (dark blue and black) which persisted until the end of the record. During this interval, there was vague evidence for $\sim 20$ min quasi-periodic variations in the spectral widths (and perhaps LOS Doppler velocities), barely discernible at the resolution of the radar measurements. If real, these perturbations may have been signatures of long-period MHD field-line resonances propagating on closed field lines (Samson et al., 1996), or less likely, weak polarisation electric fields carried by atmospheric gravity waves generated by the AWFC.

Echoes with low spectral widths have been variously associated with the main ionospheric trough (Ruohoniemi et al., 1988), the diffuse auroral oval (Jayachandran et al., 2000; Uspensky et al., 2001), and the discrete and diffuse auroral oval (Parkinson et al., 2002). In this particular case, the band of scatter with low spectral widths overlapped the equatorward edge of the diffuse auroral oval. The latter corresponds to the field-aligned poleward wall of the main ionospheric trough, especially during the pre-midnight hours (Rodger et al., 1986; Dudeney and Rodger, 1988). Hence, we surmise that the echoes were associated with ionospheric irregularities drifting slowly westward in the main ionospheric trough.

So far we have concentrated on observations made using the most eastward looking beam 15 . They revealed a narrow flow channel with $v_{\mathrm{LOS}}$ approaching up to $500 \mathrm{~m} \mathrm{~s}^{-1}$ at $\sim-64^{\circ} \Lambda$. However, the equivalent RTI plots for the western most beam 0 (and others not shown) revealed a narrow flow channel with $v_{\mathrm{LOS}}$ receding up to $450 \mathrm{~m} \mathrm{~s}^{-1}$ at $\sim-67^{\circ} \Lambda$. The associated scatter also had moderate spectral widths (50$150 \mathrm{~m} \mathrm{~s}^{-1}$ ), but appeared at 09:56 UT, coincident with the start of an impulsive increase in the $X$ component measured by the MQI magnetometer. Clearly, it seems reasonable to surmise these observations were of the same AWFC extending across the radar FOV, with observable irregularities appearing 16-min earlier on beam 0 than beam 15 (09:56 UT vs. 10:12 UT).

It may seem surprising that the PJ/SAID was centred on $\sim-64^{\circ} \Lambda$ on beam 15 (east), yet on $\sim-67^{\circ} \Lambda$ on beam 0 (west). As Fig. 1 shows, magnetic L-shells in the TIGER FOV are inclined by $2^{\circ}$ toward lower geographic latitude in the west. This meant that the AWFC was actually aligned to within $\sim 1^{\circ}$ of the geographical zonal direction. However, we attach no physical meaning to this because the AWFC probably overlapped the equatorward boundary of the auroral oval, a feature statistically located at lower magnetic latitude toward the east in the pre-midnight sector. Hence, the geographic zonal alignment was a coincidence.

In summary, an analysis of RTI plots shows that an AWFC occurred during 09:56 to 11:08 UT. Scatter associated with the AWFC appeared on beam 0 at 09:56 UT, but not on beam 15 until 10:12 UT. However, the dynamics of the event were very well defined on beam 15 . The observations of $v_{\text {LOS }}$ imply there was a narrow jet $\left(\sim 2^{\circ} \Lambda\right)$ of westward drift $>1 \mathrm{~km} \mathrm{~s}^{-1}$ with longitudinal extent $>20^{\circ}$. The AWFC must have had an extent of at least $1.3 \mathrm{~h}$ in MLT. The DMSP observations suggest the AWFC overlapped the equatorward edge of the diffuse auroral oval, a feature normally aligned with the poleward wall of the main ionospheric trough in the evening sector. The end of the event was marked by a steplike increase in backscatter power, and a step-like decrease in $v_{\text {LOS }}$ and spectral width. Unfortunately, other radars in the SuperDARN network were either not working, or they recorded sparse scatter, or were too far away in MLT, to further characterise the event.

\subsection{Standard beam-swinging analysis}

Figure 4 shows two-dimensional flow vectors estimated along TIGER beam 4 , the magnetic meridian pointing beam, using the $v_{\text {LOS }}$ values measured on all radar beams, and the beam-swinging technique described by Ruohoniemi et al. (1989). The flow speeds have been colour-coded using intervals of $50 \mathrm{~m} \mathrm{~s}^{-1}$, and the results for Substorm 2 are not shown because there was no evidence for an AWFC occurring then. The beam-swinging technique assumes fairly 


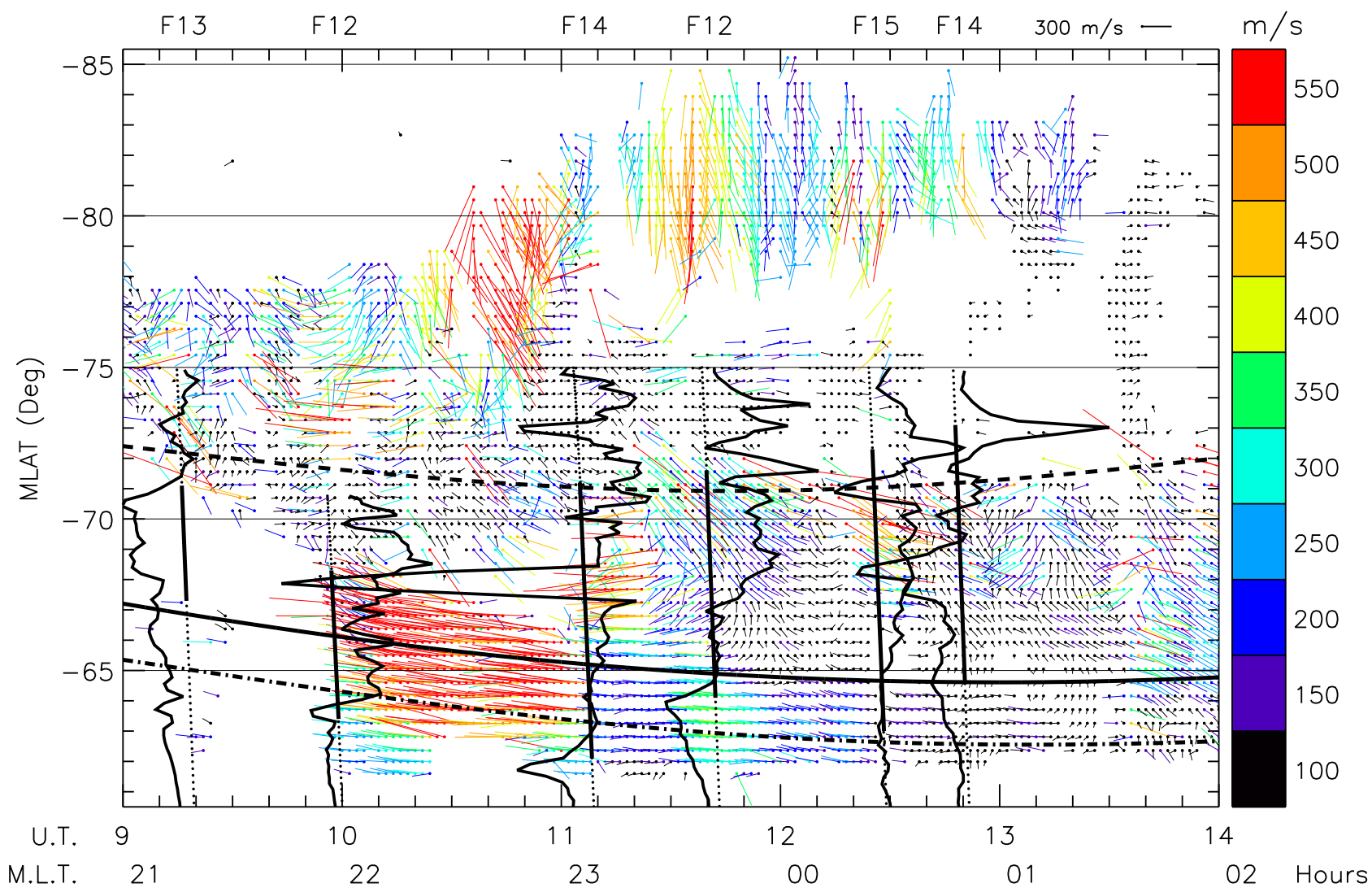

Fig. 4. Two-dimensional flow vectors estimated along TIGER beam 4 using the beam-swinging technique at 2-min time resolution during 09:00 to 14:00 UT on 27 February 2000. The solid dots correspond to the time and latitude of the velocity estimate, and the flows were in the direction of the lines leaving the dots. Flows directed toward the right were eastward, and toward the bottom, equatorward. The flow speeds were colour-coded from $<125 \mathrm{~m} \mathrm{~s}^{-1}$ (black) to $>525 \mathrm{~m} \mathrm{~s}^{-1}$ (red), and the linear scale for an eastward flow of $300 \mathrm{~m} \mathrm{~s}^{-1}$ is shown at top right. As in Fig. 3, the six bold diagonal line segments represent the location of the auroral oval identified along nearby transits of the DMSP satellites. The fluctuating black curves represent the DMSP ion drift measurements made transverse to the satellite tracks (west to the left). As in Fig. 1, Starkov's (1994) model auroral oval boundaries have been superimposed.

laminar flows with uniform velocity along magnetic L-shells (Freeman et al., 1991), and the distribution of $v_{\text {LOS }}$ in the full scans was usually consistent with this assumption. However, many of the velocity fluctuations are probably artifacts caused by an inability of the technique to reproduce smallscale and short-lived features. Nevertheless, the major trends are representative of the actual flows.

The same DMSP identifications of the auroral oval superimposed in Fig. 3 have been superimposed in Fig. 4 (diagonal black lines). DMSP ion drift measurements of the velocity component transverse to the orbital trajectories have also been superimposed, with speed proportional to the distance from the orbital trajectories. Lastly, the auroral oval boundaries (black) given by the Starkov (1994) model are also included for reference, namely the poleward boundary of discrete aurora (dashed curve), the equatorward boundary of discrete aurora (solid curve), and the equatorward boundary of diffuse aurora (dashed-dotted curve).

Figure 4 shows that during 11:15 to $13: 25 \mathrm{UT}$, the polar cap flows poleward of $-77^{\circ} \Lambda$ were persistently toward the equator, having speeds of $\sim 300 \mathrm{~m} \mathrm{~s}^{-1}$ and more. These were familiar antisunward (but slightly duskward) flows occurring in the cross polar cap jet during $B_{z}$ weakly negative, but sometimes positive conditions. They may represent flow bursts directly driven by day- or night-side reconnection, and were delayed until the substorm recovery phase (Fox et al., 1999). At lower latitudes, and other times, the polar cap flows were very erratic, and probably poorly determined. However, they had a strong bias toward the equator, and a very weak bias toward the west. A strong equatorward flow burst to speeds of $\sim 1 \mathrm{~km} \mathrm{~s}^{-1}$ occurred during 10:35 to 10:55 UT and between $-75^{\circ} \Lambda$ and $-81^{\circ} \Lambda$. This flow burst commenced on open field lines during the expansion phase of Substorm 1 (Fig. 2e). Beyond 11:20 UT, the flows in the auroral ionosphere $\left(\sim-65^{\circ}\right.$ to $\left.-71^{\circ} \Lambda\right)$ were still toward the equator, but they developed a strong eastward component. This suggests that beam 4 passed through a radar ana$\log$ of the Harang discontinuity, a feature clearly seen near $11: 45 \mathrm{UT}$ at $\sim-68^{\circ} \Lambda$.

Figure 4 also reveals that the AWFC overlapped the auroral and subauroral ionosphere. During 09:56 to 11:08 UT, very large $\left(>1 \mathrm{~km} \mathrm{~s}^{-1}\right)$ westward drifts centred on $\sim-65^{\circ} \Lambda$ 


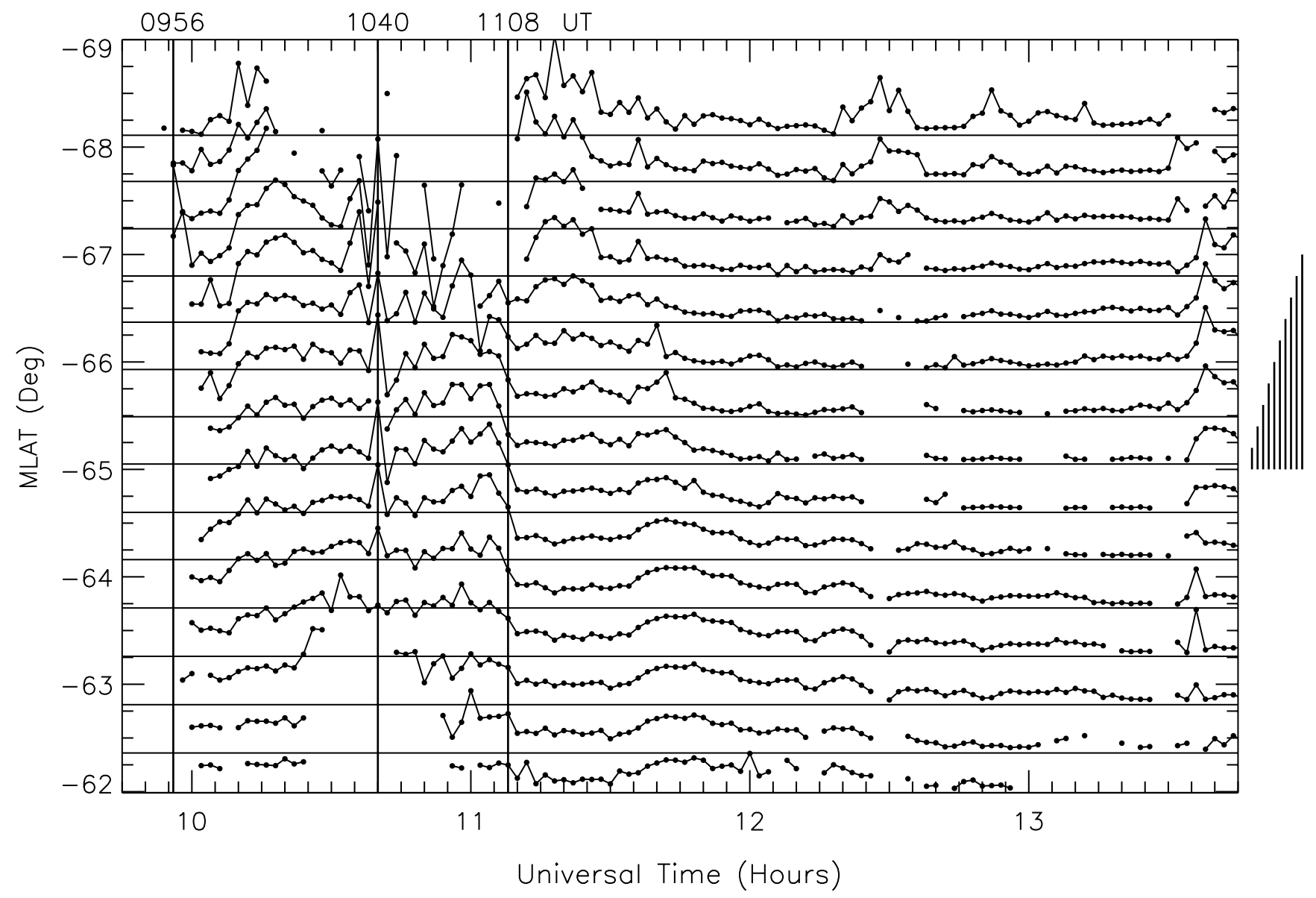

Fig. 5. Stack plot of flow speeds estimated along TIGER beam 4 using the beam-swinging technique at 2-min time resolution during 09:45 to $13: 45$ UT on 27 February 2000. The flow speeds were calculated at intervals of just under $0.5^{\circ} \Lambda$, and the scale used was $1 \mathrm{~km} \mathrm{~s} \mathrm{~s}^{-1}$ per $1^{\circ} \Lambda$. The ascending scale at right shows speeds of $200,400, \ldots, 2000 \mathrm{~m} \mathrm{~s}^{-1}$.

and to the west of the Harang discontinuity occurred concurrently with Substorm 1. Another short-lived burst of westward flow occurred during 11:10 to 11:25 UT between $-67^{\circ} \Lambda$ and $-71^{\circ} \Lambda$, possibly the same substorm signature described by Sánchez et al. (1996). The drifts beyond 11:08 UT and equatorward of $-65^{\circ} \Lambda$ were mostly in the range $50-300 \mathrm{~m} \mathrm{~s}^{-1}$, and predominately westward until the start of Substorm 2 toward the end of the record.

The DMSP ion-drift measurements (black) were in reasonable agreement with the zonal velocity components measured by TIGER, when allowing for the location of the satellite trajectories relative to the radar FOV. DMSP ion-drift measurements poleward of $-75^{\circ} \Lambda$ are not shown in Fig. 4, because the trajectories rapidly traversed many degrees of longitude. The ion-drift measurements made during the first pass of the F13 spacecraft were toward the west, consistent with normal return sunward flows in the dusk sector near 19:50 MLT. During the first pass of the F12 spacecraft at 09:58 UT, the auroral flows were predominately eastward, as might be expected east of the Harang discontinuity (recall the pass was to the east of the radar FOV).

During the first pass of the F14 spacecraft at 11:06 UT, a narrow $\sim 1^{\circ}$ westward flow burst with peak speed $3.1 \mathrm{~km} \mathrm{~s}^{-1}$ was detected at 22:49 MLT and $-68^{\circ} \Lambda$. There was also a vertical upward velocity spike of $1 \mathrm{~km} \mathrm{~s}^{-1}$ (i.e. ion heating). As previously described, the same event was measured just to the east shortly afterward by TIGER, though with a much lower speed. The DMSP spectra show this event was spatially coincident with a flux depletion region (FDR) inside boundary plasma sheet precipitation, as described by Sánchez et al. (1996). Enhanced westward drifts occur on closed field lines in FDRs (see Fig. 4 of Sánchez et al., 1996), and convection reversals and arc intensifications at their poleward edges. Lastly, enhanced westward drifts correspond to eastward electrojets, which can be mistaken for the recovery phase of substorms. Hence, the present event may only appear to have occurred at the end of recovery phase of Substorm 1.

Ion-drift measurements made during the other three satellite passes were basically consistent with the eastward auroral flows and slower westward subauroral flows observed by TIGER (i.e. the flow reversal boundary).

It is difficult to judge when variations of flow speed occurred during and after the AWFC using the results shown in 


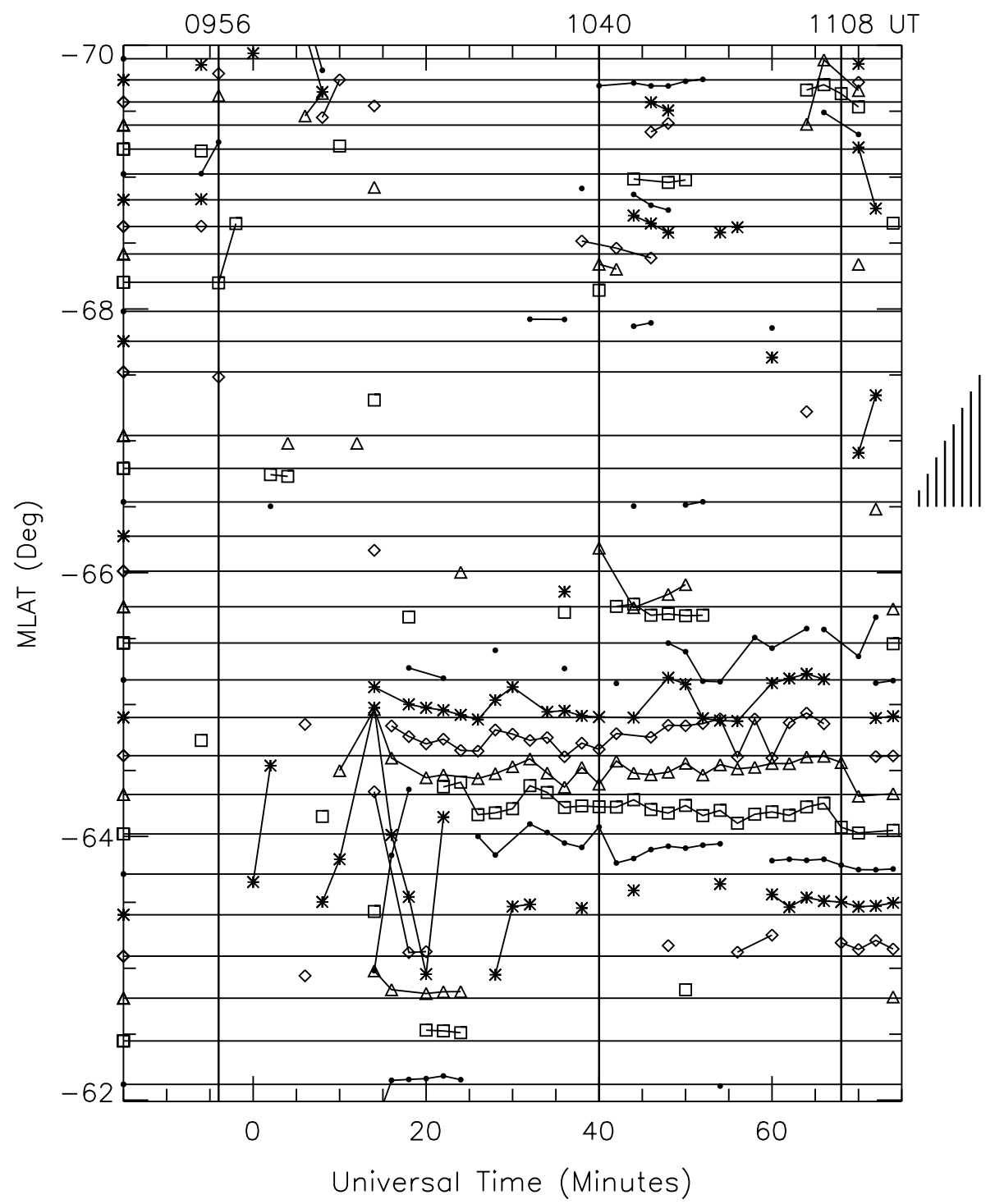

Fig. 6a. Refined beam-swinging analysis (see text) using the LOS Doppler velocities recorded on beam 15 (east). Alternating symbols were used for velocities calculated at different magnetic latitudes and are identified by the symbol superimposed on the left ordinate at the corresponding latitude (e.g. open squares represent velocities at $-64^{\circ} \Lambda$ ). The scale used was $4 \mathrm{~km} \mathrm{~s}^{-1}$ per $1^{\circ} \Lambda$, and the ascending scale at right shows speeds of $500,1000, \ldots, 4000 \mathrm{~m} \mathrm{~s}^{-1}$. The time base is in minutes, commencing at 10:00 UT, and the abscissa has tick marks at 5-min intervals of UT.

Fig. 4. Hence, Fig. 5 is an expanded view of flow speeds occurring at subauroral latitudes only. The flow speeds were calculated at the maximum time resolution of $2 \mathrm{~min}$, corresponding to the time separating full scans. The speeds are shown in stack plot form using a scale of $1 \mathrm{~km} \mathrm{~s}^{-1}$ per $1^{\circ} \Lambda$. An ascending scale of vectors of length $200,400, \ldots$, $2000 \mathrm{~m} \mathrm{~s}^{-1}$ is shown at right. Using $\boldsymbol{v}=\boldsymbol{E} \times \boldsymbol{B} / B^{2}$, these speeds correspond to electric fields of strength $\sim 11.9$, $23.7, \ldots, 118.7 \mathrm{mV} \mathrm{m}^{-1}$ inside the TIGER FOV.

At 09:56 UT, the nominal start of the AWFC, the flow speeds were probably no more than $\sim 250 \mathrm{~m} \mathrm{~s}^{-1}$. The speeds were larger at higher latitudes, rapidly increasing to $\sim 600 \mathrm{~m} \mathrm{~s}^{-1}$ by $10: 12 \mathrm{UT}$. The speeds continued to grow, peaking to nearly $900 \mathrm{~m} \mathrm{~s}^{-1}$ by 10:18 UT. A velocity spike of $\sim 1.3 \mathrm{~km} \mathrm{~s}^{-1}\left(77 \mathrm{mV} \mathrm{m}^{-1}\right)$ occurred at 10:40 UT, marking the maximum flow speeds estimated using this particular analysis. Using a nominal half-width of $\sim 100 \mathrm{~km}$ for the flow channel (to be justified), this corresponds to a peak electric potential $>7.7 \mathrm{kV}$. At 11:04 UT, the flow speed was $\sim 800 \mathrm{~m} \mathrm{~s}^{-1}$, but rapidly declined to $\sim 200 \mathrm{~m} \mathrm{~s}^{-1}$ by 11:10 UT, the nominal end of the AWFC. The region of high speed was broader in latitude at the start of the AWFC, and its location decreased in latitude by $\sim 2^{\circ} \Lambda$ towards its end.

At 11:18 UT, the flow speed again peaked to $\sim 1 \mathrm{~km} \mathrm{~s}^{-1}$ during the other short-lived flow burst near $-68^{\circ} \Lambda$. At 11:42 UT, the low-latitude flow speeds also peaked again, but only to $\sim 400 \mathrm{~m} \mathrm{~s}^{-1}$ near $-64^{\circ} \Lambda$. Perhaps this peak was associated with the lesser auroral intensification to $-83 \mathrm{nT}$ 


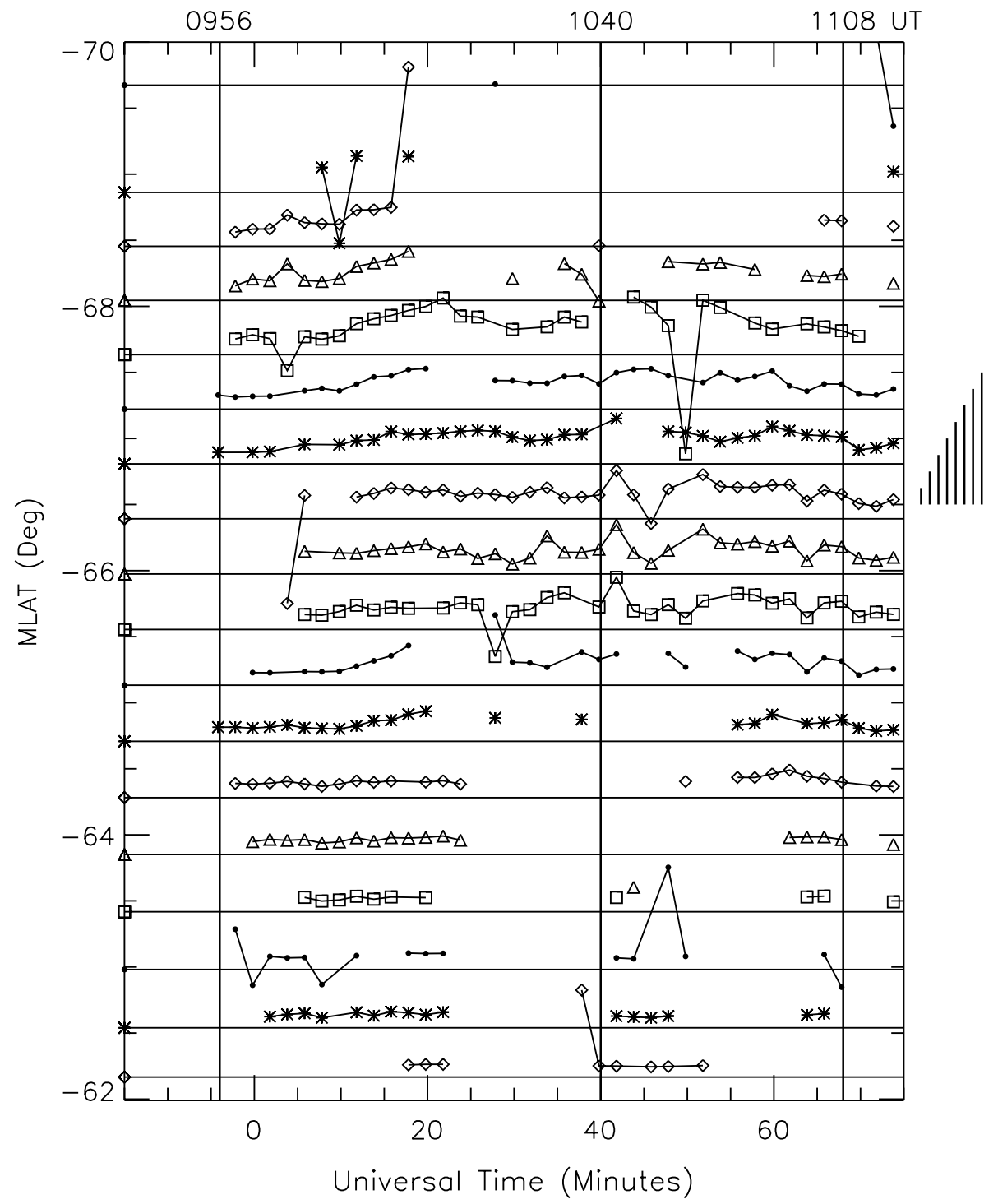

Fig. 6b. The same as Fig. 6a except for beam 0 (west).

beginning near 11:28 UT (Fig. 2e). Thereafter, the subauroral flows steadily decayed, reaching values $<50 \mathrm{~m} \mathrm{~s}^{-1}$ during 13:00 UT.

Consulting the DICM model suggests that prior to 10:30 UT, there should have been westward flows up to $400 \mathrm{~m} \mathrm{~s}^{-1}$ equatorward of $-65^{\circ} \Lambda$. However, after passing through the Harang discontinuity at 11:55 UT, the subauroral flows should have rotated toward the east. Clearly, the westward flows observed during the AWFC were much larger than typical convection speeds for this sector, and the subsequent subauroral flows were in the opposite direction to those normally observed past the Harang discontinuity. The persistence of the AWFC on closed magnetic field lines is inconsistent with nightside reconnection as a driver for the event.

\subsection{Refined beam-swinging analysis}

The standard beam-swinging analysis applied in the preceding section assumed uniform velocity along magnetic Lshells (Ruohoniemi et al., 1989). However, from an examination of beam 15 observations (Fig. 3), and equivalent observations for beam 0 , we know that the AWFC was a very narrow feature on beam $15\left(\sim 1^{\circ} \Lambda\right)$, somewhat broader on beam $0\left(\sim 2^{\circ} \Lambda\right)$, and aligned in the geographic zonal direction. The DMSP ion drift measurements also suggest the standard beam-swinging analysis (Fig. 4) underestimated the magnitude of the westward drifts, smearing them over a greater range of magnetic latitude. Hence, we applied the following simpler beam-swinging analysis to further scrutinise the LOS Doppler shifts. The geographic westward drift, $v_{w}$, in the flow channel was calculated for every line-of-sight veloc- 
ity, $v_{\mathrm{LOS}}$ using the following equation:

$v_{w i, j}=\left(v_{\mathrm{LOS} i, j}--v_{e q}\right) / \sin \left(\theta_{i}-\varphi\right)$,

where $i$ varies over all 16 beams, and $j$ over all ranges with ionospheric scatter. $\theta_{i}$ is the angle between the geographic meridian and the beam direction, $i$ (e.g. $24.3^{\circ}$ for beam 15 ), $\varphi \approx 1^{\circ}$ is a correction equal to the difference between the orientation of the flow channel and the geographic east-west direction, and $v_{e q} \approx 80 \mathrm{~m} \mathrm{~s}^{-1}$ is an estimate of the equatorward migration of the flow channel, as revealed in Fig. 4. As $\theta_{i}-\varphi$ approaches $0^{\circ}$ for beams 7 and $8, v_{w}$ becomes very large and changes asymmetrically for even small errors in $v_{e q}$ and $\varphi$. Hence, reasonable estimates of $v_{e q}$ and $\varphi$ were obtained by suppressing the discontinuity in $v_{w}$ centred on the imaginary beam half-way between beams 7 and 8, and pointing perpendicular to the flow channel.

Figure 6a shows a stack plot of beam 15 results calculated using Eq. (1). The main part of the AWFC was centred near $64.5^{\circ} \Lambda$. It was $\sim 1^{\circ} \Lambda$ wide, and $v_{w}$ was often $\sim 1 \mathrm{~km} \mathrm{~s}^{-1}$. However, during 10:00 to 10:22 UT at $\sim 63^{\circ} \Lambda$, there is some evidence for unusually large and temporally structured westward flows, perhaps peaking to $\sim 6 \mathrm{~km} \mathrm{~s}^{-1}$ at 10:14 UT. Note that we have excluded all points for which the relative error in $v_{\mathrm{LOS}}$ was greater than $50 \%$, and some of the unusually large velocities persist when applying even more stringent criteria. However, some of the large velocities are artifacts caused by real, meridional ionospheric flow components perpendicular to the flow channel. These velocity components greatly amplify $v_{w}$, especially for small $\theta_{i}-\varphi$. Lastly, because of the subsequent absence of backscatter at the equatorward edge, we cannot tell whether unusually large velocities were present beyond $~ 10: 30$ UT. In light of this analysis, and the $3.1 \mathrm{~km} \mathrm{~s}^{-1}$ velocity spike measured by the F14 spacecraft, we speculate that there were larger, more structured flows than portrayed in Fig. 4.

Figure $6 \mathrm{~b}$ is the results of the same analysis applied to the same time and range windows, but for the western most beam 0 . The main part of the AWFC was centred near $67^{\circ} \Lambda$. It was $\sim 2.5^{\circ}$ wide, and $v_{w}$ was often $\sim 1 \mathrm{~km} \mathrm{~s}^{-1}$. Again, some of the unusually large values of $v_{w}$ may have been caused by real ionospheric flows perpendicular to the flow channel. It is interesting that the velocity spike at 10:40 UT in Fig. 4 was caused by large Doppler shifts on the beams nearly bisecting the radar FOV. Combined, this suggests that there may have been a lot of structure associated with the AWFC that cannot be resolved without using a high resolution, dual radar system.

Clearly, the signatures of the AWFC were narrower, and possibly more structured closer to the Harang discontinuity (Fig. 6a), and became broader at earlier MLT (Fig. 6b). The velocities were largest on the eastern-most beams, and were probably underestimated using the standard analysis, Fig. 4.

Lastly, beam 15 results for 11:30 to 12:05 UT obtained using the same analysis (not shown) show a westward velocity enhancemnet to $\sim 700 \mathrm{~m} \mathrm{~s}^{-1}$, propagating equatorward from $\sim 66^{\circ} \Lambda$ to $62^{\circ} \Lambda$ at a similar velocity (c.f. Fig. 5). The event was initiated at the onset of the lesser intensification following Substorm 1 (Fig. 2e). We speculate that the associated current surge launched an atmospheric gravity wave which carried a meridional polarisation field.

\subsection{Other ground-based observations}

Figure 7a shows a range-time-intensity (RTI) plot of the Doppler spectral width $\left(\mathrm{m} \mathrm{s}^{-1}\right)$ measured on TIGER beam 15 during 08:00 to 16:00 UT on 27 February 2000. A shorter interval of this data was shown in Fig. 3c, but is shown again for comparison with (b), the induction coil magnetogram showing ultra-low frequency (ULF) wave activity recorded nearby at MQI, and (c) the various critical frequency parameters scaled from MQI routine ionograms recorded every $15 \mathrm{~min}$. MQI $\left(-65^{\circ} \Lambda\right)$ has the same magnetic latitude as range cell $26(1350 \mathrm{~km})$ of beam 15 , located $406 \mathrm{~km}$ away. However, it is meaningful to compare observations made at these two locations, even though the detailed ionospheric electrodynamics must be different.

Figure 7 a shows there was a burst of large spectral widths $\left(>200 \mathrm{~m} \mathrm{~s}^{-1}\right)$ during 10:06 to $10: 12 \mathrm{UT}$ at latitude $-62^{\circ}$ to $-64^{\circ} \Lambda$. This was followed by an interval of moderate spectral widths $\left(150-200 \mathrm{~m} \mathrm{~s}^{-1}\right)$ at $\sim-64^{\circ} \Lambda$ during 10:08 to 11:12 UT (the AWFC). The next major episode of auroral scatter with large spectral widths $\left(>150 \mathrm{~m} \mathrm{~s}^{-1}\right)$ suddenly commenced at 13:36 UT, coincident with the onset of Substorm 2 (c.f. Fig. 2e).

An initial qualitative comparison suggests the variations in spectral width at $\sim-65^{\circ} \Lambda$ (Fig. 7a) were roughly coincident with the variations in ULF wave activity recorded at MQI (Fig. 7b). A dynamic power spectrogram of the MQI magnetometer response (not shown) confirms that there were two major episodes of ULF wave activity coincident with Substorms 1 and 2. When allowing for spatial integration across the large, effective FOV of the ground-based magnetometer $(\sim 300 \mathrm{~km})$ (Ponomarenko et al., 2001), and its spatial separation from beam 15 , the agreement between the two kinds of data is reasonable. This suggests that the spectral width enhancements were related to bursts of broad-band ULF wave activity, and not small-scale convective turbulence (i.e. if such a distinction exists).

DMSP spacecraft data confirm that the many kinds of ULF wave activity shown in Fig. 7b occurred on closed field lines in the auroral oval. A detailed analysis of the different kinds of wave activity is beyond the scope of this study. However, Figure $7 \mathrm{~b}$ shows that there was a burst of Pi2 waves (40-150 s) near the start of Substorm 1, 09:50 UT, and Pi1 (1-40 s) waves quickly developed (PiB evolving into $\mathrm{PiC}$ ), becoming most intense during 10:45 to 11:05 UT. Pi3 (540 min) (or Ps6) waves were present throughout the event and are clearly evident during the recovery phase up until 12:32 UT (Fig. 7b). Concurrent signatures of Pi3 wave activity were also apparent in the radar measurements (Figs. 3 and $7 \mathrm{a}$ ). Figure $7 \mathrm{~b}$ also shows that there was a burst of Pi2 waves near the start of Substorm 2, 13:33 UT, and a 2-h episode of intense Pi1, Pi2, and Pi3 wave activity fol- 


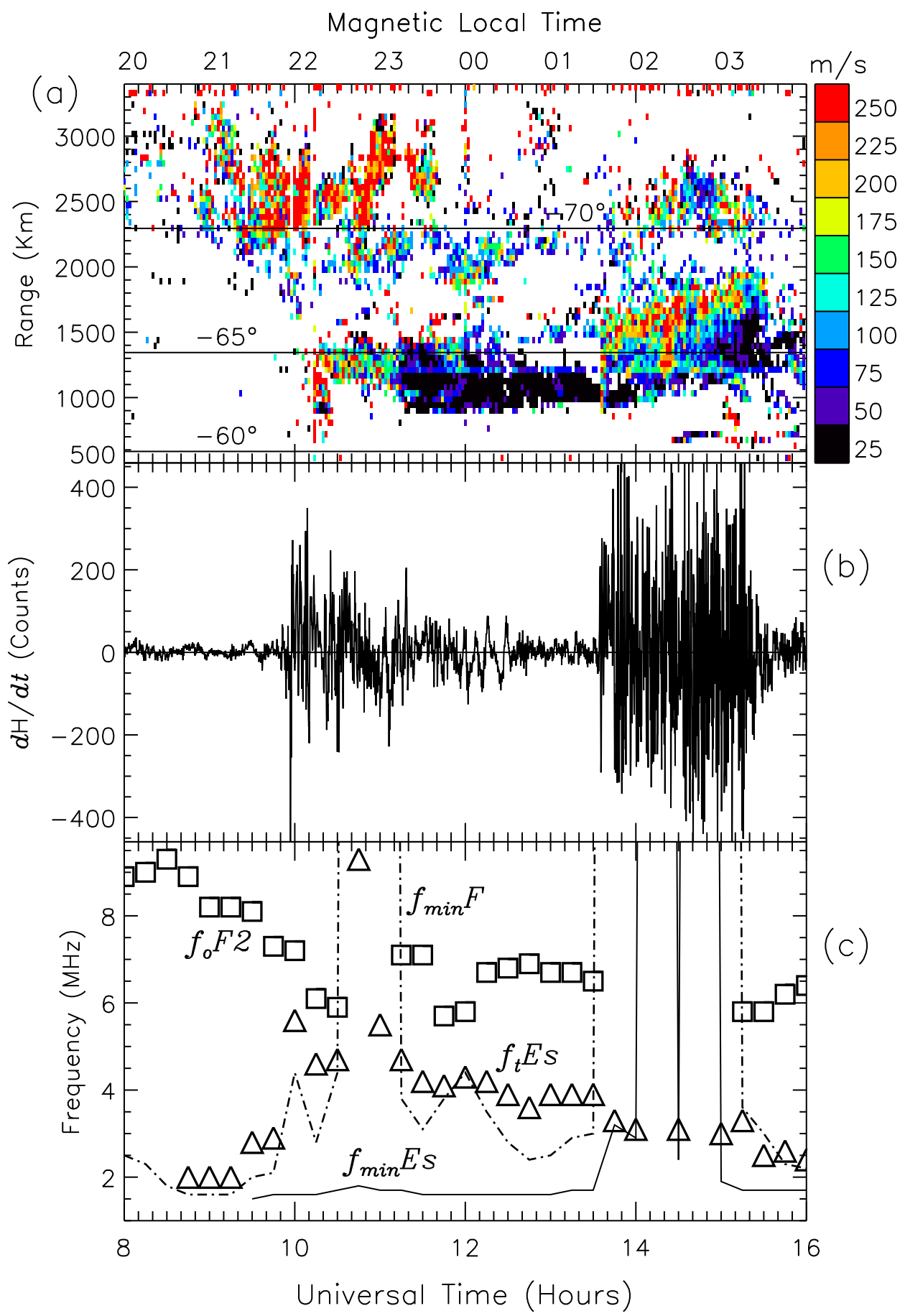

Fig. 7. (a) RTI plot of Doppler spectral width $\left(\mathrm{m} \mathrm{s}^{-1}\right)$ recorded every 2 min on TIGER beam 15 during 08:00 to 16:00 UT on 27 February 2000. (b) The time derivative of the geomagnetic $H$ component measured at 1-s intervals by an induction coil magnetometer located at MQI. (c) The critical frequency parameters $f_{\min } E s$ (continuous line), $f_{\min } F$ (dash-dot-dash line), $f_{t} E s$ (open triangles), and $f o \mathrm{~F} 2$ (open squares), all scaled from routine ionograms recorded at 15-min intervals by an analogue ionosonde located at MQI. The abscissas have tick marks at 10-min intervals of UT, and nominal values of MLT at MQI are shown at top.

lowed shortly thereafter, lasting until near the end of recovery phase, $\sim 15: 33$ UT.

The frequency parameters shown in Fig. 7c include a measure of ionospheric absorption, $f_{\min } E s$ (continuous line), a measure of ionospheric absorption and blanketing $E s, f_{\min } F$ (dash-dot-dash line), the top frequency of auroral Es traces, $f_{t} E s$ (open triangles), and $f_{o} \mathrm{~F} 2$ (open squares). The behaviour of these parameters revealed two major absorption events, the first occurring during 10:30 to 11:15 UT (i.e. Substorm 1), and the second occurring during 13:30 to 15:15 UT 
(i.e. Substorm 2). The times of major absorption were defined by increases in the parameter $f_{\min } F$ to at least beyond the parameter $f o \mathrm{~F} 2$. However, it is possible that the F-region traces were lost because ion-neutral friction heating resulted in the loss of F-region ionisation.

The parameter $f_{o} \mathrm{~F} 2$ was depressed during Substorm 1, perhaps due to an enhanced recombination rate associated with the AWFC located just equatorward of MQI. The major absorption event during Substorm 1 was preceded by an episode of auroral $E s$ with $f_{t} E s$, increasing to $5.6 \mathrm{MHz}$ at 10:00 UT, near the substorm onset. At 10:45 UT, $f_{t} E s$ reached a maximum value of $9.3 \mathrm{MHz}$, close to the peak expansion phase and the largest, smoothed velocities in the AWFC. Absorption during Substorm 2 was even more intense, resulting in the loss of auroral $E s$ traces as well as F-region traces. We attribute these absorption events to energetic particle precipitation intensifying in the auroral oval located above MQI, just poleward of the AWFC. Note that nearly continuous ionospheric scatter was recorded by the oblique looking TIGER radar during these absorption events.

An analysis of coincident vertical TEC measurements (not shown) made using ground-based receivers located at MQI and Hobart also suggest that the auroral oval was located above, or nearby, MQI during the study period. Observations made under a broad range of geomagnetic conditions suggest that the centre of the main ionospheric trough was probably located $\sim 2-5^{\circ}$ further equatorward during 27 February. This is consistent with alignment of the AWFC with the poleward edge of the trough, and overlapping the equatorward edge of the diffuse auroral oval.

\section{Discussion and conclusions}

An AWFC resembling a PJ/SAID occurred simultaneously with Substorm 1 on 27 February 2000. We summarise the observed sequence of events, and provide plausible explanations for their meaning as follows.

Variations in the geomagnetic $X$ component measured at MQI $\left(-65^{\circ} \Lambda\right)$ showed manifestation of Substorm 1 occurring in the evening sector ( 22:00-23:00 MLT) during 09:58 to 11:10 UT. This substorm may have been triggered by a weak $B_{z}$ northward turning, following a succession of deeper $B_{z}$ southward turnings to less than $-4 \mathrm{nT}$. Surprisingly, the geomagnetic $X$ and $Y$ components at MQI showed no obvious growth-phase signatures; rather the onset of Substorm 1 was preceded by a $\sim 60-\mathrm{nT}$ northward impulse in the $X$ component, peaking at 09:58 UT. The impulse was coincident with the start of a dispersionless particle injection observed by the LAN-L 1989-046 geosynchronous spacecraft located at 6.6 $R_{E}$ and 22:53 MLT. The geomagnetic $X$ component subsequently swung deeply negative, indicative of substorm onset. Recovery phase commenced at 10:53 UT, and the substorm finished at 11:10 UT.

Why was there no clear growth phase signature in the MQI geomagnetic $X$ component preceding the onset of Substorm 1? At this time MQI was located at 21:00 MLT, perhaps too far to the east to detect the gradual growth of the DP 2 eastward electrojet, yet too far to the west to detect the gradual growth of the DP 2 westward electrojet. However, consider an alternative possibility. The growth phase signature of Substorm 1 may have been masked by the effects of the AWFC. Near the start of Substorm 1, 09:53 to 10:02 UT, there was a positive deflection in the $X$ component, consistent with an AWFC driving an eastward Hall current. Ionneutral friction must have rapidly elevated the F-region recombination rate, reducing the ionospheric electron density, and thus ionospheric conductivity. Hence, beyond 09:58 UT, the effect of the eastward Hall current on the magnetometer began to diminish, whereas the effects of the westward electrojet rapidly increased. By 10:02 UT, the latter began to have a greater effect on the magnetometer than the eastward Hall current driven by the AWFC.

The MQI $Z$-component variations were opposite in sign to the $X$-component variations during the intervals dominated by eastward Hall and westward electrojet currents. They imply these currents were centred just poleward of MQI where the ionospheric conductivity was larger deeper into the auroral oval. The beam-swinging vectors may have been poorly determined just poleward of the AWFC, but Fig. 4 shows there was evidence for strong eastward and equatorward flows during 10:20 to 11:00 UT between $-67.5^{\circ}$ and $-71.5^{\circ} \Lambda$. Moreover, ion-drift measurements made during the first passes of the F12 and F14 spacecraft also showed strong eastward flows closer to midnight just poleward of the AWFC. Combined with conductivity enhancements, these eastward flows are consistent with the familiar $-X$ deflections observed at MQI.

Figure 3 showed TIGER observed signatures of an AWFC in the backscatter power, LOS Doppler velocity, and Doppler spectral width, simultaneous with the MQI magnetometer signatures of the current wedge forming during Substorm 1. Although scatter associated with the AWFC was not observed on the eastern-most beam 15 until 10:12 UT, it was observed earlier at 09:56 UT on the western-most beam 0 . On beam 15 , the scatter was $\sim 2^{\circ} \Lambda$ wide, centred on $-64^{\circ} \Lambda$, and $v_{\mathrm{LOS}}$ was up to $500 \mathrm{~m} \mathrm{~s}^{-1}$ towards the radar. On beam 0 , the scatter was centred on $-67^{\circ} \Lambda$, and $v_{\mathrm{LOS}}$ was up to $450 \mathrm{~m} \mathrm{~s}^{-1}$ away from the radar. The largest values of $v_{\mathrm{LOS}}$ were confined to a very narrow channel $<1^{\circ} \Lambda$ wide. These observations implied very large westward drifts $\left(>1 \mathrm{~km} \mathrm{~s}^{-1}\right)$ aligned parallel to the equatorward edge of the auroral oval. DMSP measurements of precipitating particles confirmed the narrow flow channel probably overlapped the equatorward edge of the diffuse auroral oval. MQI ionosonde and TEC measurements also helped to validate this interpretation.

Figure 3 showed that for $\sim 2 \mathrm{~h}$ beyond the end of the AWFC, there was a channel of scatter with low spectral widths resembling the scatter normally associated with the main ionospheric trough (Ruohoniemi et al., 1988). The irregularities were also slowly drifting toward the west at $\sim 100 \mathrm{~m} \mathrm{~s}^{-1}$ in a region located to the east of the Harang discontinuity, whereas statistical convection models indicate eastward flows dominate this region. It seems reasonable to 
speculate the AWFC contributed to the depletion of plasma in the main ionospheric trough, with the associated electrodynamics persisting at MLTs east of the Harang discontinuity. The subsequent, slower westward flows marked a subauroral regime found equatorward of the influence of magnetospheric convection (i.e. the flow reversal boundary). The main ionospheric trough and the plasmapause were probably located in proximity to this band of scatter $\left(\sim-63^{\circ} \Lambda\right.$ on beam 15).

The analysis of full-scan results, Fig. 5, revealed that the magnitude of flows in the AWFC must have grown during the 22-min interval, 09:56 to 10:18 UT. There was an especially sharp rising edge at 10:08 UT near the poleward extremity of the AWFC, coincident with a peak in the flux of hot protons measured by the LAN-L 1989-046 spacecraft. Peak flows occurred at 10:40 UT, coincident with a step-like decrease in the flux of hot protons at 10:40 UT. However, the more refined analysis of Doppler shifts, Figs. 6a and b, revealed there were poorly resolved, small-scale motions during the event, with evidence for speeds $>4 \mathrm{~km} \mathrm{~s}^{-1}$ at substorm onset near the equatorward edge of the AWFC. The AWFC migrated toward lower latitude at $\sim 80 \mathrm{~m} \mathrm{~s}^{-1}$, and there was a slight tendency for the width of the flow channel to converge in latitude with time. At the end of the recovery phase, the flows decayed rapidly during the 6-min interval 11:04 to $11: 10 \mathrm{UT}$. The subsequent westward flows, probably associated with the main trough, trended toward lower values during the following two-hour interval. The life time of the main part of the AWFC was 74 min (09:56 to 11:10 UT).

Interestingly, the DMSP F14 spacecraft measured a $3.1 \mathrm{~km} \mathrm{~s}^{-1}$ westward flow burst at the end of the recovery phase, 11:06 UT. This flow burst was located well inside the discrete auroral oval, a region thought to map to closed field lines. Hence, this event was probably not directly driven by nightside reconnection, and may constitute a short-lived AWFC. Its behaviour was similar to that of the large westward flows coincident with flux depletion regions (FDRs) occurring in the boundary plasma sheet (Sánchez et al., 1996).

The AWFC observed during 09:56 to 11:10 UT had much in common with the observed characteristics of PJ/SAIDs, and the theoretical expectations of Anderson et al. (1993) and De Keyser (1999). For example, the AWFC was broader in latitude toward earlier MLT, and had a slight tendency to converge with time (Anderson et al., 1993). The gradual equatorward movement of the flow channel at $\sim 80 \mathrm{~m} \mathrm{~s}^{-1}$ is consistent with the earthward migration of a hot ion plasma front toward the plasmapause, and the PJ/SAID took at least 22 min to fully develop (De Keyser, 1999). However, unlike earlier satellite observations which show that PJ/SAIDs do not occur until the recovery phase, our event commenced at substorm onset and finished at the end of recovery phase. Does our AWFC only briefly satisfy the Anderson et al. definition of a PJ/SAID (i.e. westward drifts $>1 \mathrm{~km} \mathrm{~s}^{-1}$ ), because the hot plasma front never reaches the plasmapause prior to the end of the recovery phase? The event remained relatively weak and structured, but it might have been the precursor of a true PJ/SAID which never fully developed.
The AWFC reported here also had much in common with the substorm-associated radar auroral surges (SARASs) observed using a dual VHF radar (Freeman et al., 1992). SARASs are E-region westward flow surges with peak drifts of $\sim 1 \mathrm{~km} \mathrm{~s}^{-1}$ and latitudinal widths of $\sim 2-3^{\circ}$. The SARAS shown in Fig. 4 of Freeman et al. (1992) is surprisingly similar to the AWFC shown in our Fig. 4. SARAS occur in the afternoon sector, and when allowing for westward phase speeds of $1-4 \mathrm{~km} \mathrm{~s}^{-1}$, the starts of SARAS are probably synchronised to substorm onset. Our AWFC was not directly driven by magnetic reconnection, but occurred in the premidnight sector, close to the initial hot particle injection near substorm onset. AWFC, SARAS, and PJ/SAIDs may be different manifestations of closely related (or the same) electrodynamic process.

Unlike previous measurements of PJ/SAIDs made using polar orbiting spacecraft, the SuperDARN technique is capable of observing the evolution of related events with good resolution in both space and time. Unfortunately, the AWFC reported here was not observed with other radars in the network, including the conjugate Northern Hemisphere radars. This is due to instrument failures, the absence of suitable backscatter, or the inappropriate MLT or latitude of the radars. Thus, we cannot say anything about the conjugacy of the AWFC, nor impose further constraints on any magnetospheric source. For now, we can only surmise our structured AWFC had a longitudinal extent $>20^{\circ}$, or at least $1.3 \mathrm{~h}$ in MLT.

The importance of the ionosphere in generating and regulating the lives of PJ/SAIDs can be understood as follows. First, note the F-region conductivity can be larger than the E-region conductivity in the nightside ionosphere ( $\mathrm{Du}$ and Stening, 1999). Now consider three ionospheric regions, infinite in the zonal direction, but with different Pedersen conductivities, namely a nightside mid-latitude ionosphere with moderate conductivity, a main ionospheric trough with low conductivity, and an auroral ionosphere with large conductivity. If the magnetosphere imposes the same poleward electric field across these three regions, there will be a divergence of Pedersen current across the two junctions. Positive charge will accumulate in the equatorward wall of the trough, and negative charge in the poleward wall, until $\nabla \cdot J_{p}=0$. Hence, the poleward electric field will intensify across the trough, and there will be a subsequent increase in westward drift. The associated increase in ion-neutral friction will further reduce the Pedersen conductivity, and further increase the polarisation field, etc. In a sense, the magnetosphereionosphere coupling acts like a PJ/SAID generator, drawing energy from the magnetosphere via field-aligned currents. However, ionospheric feedback can only partly explain $\mathrm{PJ} / \mathrm{SAIDs}$ due to their concentration in the evening sector.

This electrodynamic behaviour is similar to that proposed for drifting auroral arcs in which enhanced poleward electric fields are observed in plasma-depleted regions just equatorward of the arc (Lewis et al., 1994). The divergence of Pedersen current across step-like changes in the ionospheric conductivity is partly compensated for by the upward 
field-aligned current in the arc. There is also a downward field-aligned current at the equatorward edge of the plasmadepleted region. The large westward drifts associated with FDRs (Sánchez et al., 1996) may also be governed by similar electrodynamics. Our AWFC occurred on a larger scale size, and further equatorward than the normal location of FDRs and discrete auroral arcs. However, its location overlapped the equatorward edge of the auroral oval, and discrete arcs may have been located at its poleward edge. This electrodynamic behaviour may be replicated on various scale sizes throughout the auroral and subauroral ionosphere.

Now consider the effects of solar illumination on the proposed PJ/SAID mechanism. The Sun was higher in the sky further to the west where more direct photoionisation must have suppressed the conductivity gradients across the main ionospheric trough. Hence, the polarisation fields must have been weaker. This might partly explain why the signatures of the AWFC on 27 February were strongest on the eastern most beam 0 , and weakest on the western most beam 0 .

Since the start of the AWFC was synchronised with the onset of Substorm 1, and finished at the recovery phase, it was clearly a signature of Substorm 1. However, was it actually part of the process of triggering the substorm? For example, Lui and Murphree (1998) recently proposed that cross-tail current disruption occurs via the cross-field current instability $(\mathrm{CCI})$ when the current is driven to a critical value during an appropriate half-cycle of a MHD field-line resonant wave. This occurs at the inner edge of the plasma sheet, near where AWFCs occur. Note that the magnetometer data, Fig. 2e, suggest that the AWFC commenced before substorm onset.

Are the large radial electric fields associated with AWFCs sufficient to trigger current disruption, or the onset of a magnetospheric substorm, via the CCI? This would require the associated polarisation field to initially form in the current disruption region just tailward of the ring current, and then migrate earthward (as observed). Perhaps some vortical motion occurs at the beginning of AWFCs since the associated flow shears mapping to the equatorial plane of the magnetosphere drive the Kelvin-Helmholtz instability. This explanation is analogous to that given by Samson et al. (1996).

The decametre-scale irregularities observed by SuperDARN radars are thought to be "secondary" waves generated under conditions established by the "primary" gradient-drift instability which acts on larger scale gradients (Hanuise et al., 1993; Jaychandran et al., 2000). The growth rate, $\gamma$, for gradient-drift waves is proportional to $v . \nabla n_{e} / n_{e}$, where $\boldsymbol{v}=\boldsymbol{E} \times \boldsymbol{B} / B^{2}$ is the ion drift velocity (Kelley et al., 1982). Hence, gradient drift irregularities will grow most rapidly when the plasma drifts in the same direction as the plasma density gradient, and a radar beam must be parallel or antiparallel to this direction to detect the strongest perturbations in electron density. Assuming that the velocity term dominated the growth of primary gradient drift waves in the main ionospheric trough, this explains why the greatest backscatter power was observed on the most zonal beams (see Fig. 1).

A step-like transition in backscatter power, LOS Doppler velocity, and Doppler spectral width occurred at 11:08 UT, the end of the AWFC. Prior to this transition, the beam 15 power had moderate SNR $<20 \mathrm{~dB}$, the values of $v_{\mathrm{LOS}}$ were up to $500 \mathrm{~m} \mathrm{~s}^{-1}$ away, and the spectral widths were moderate to large, $100-200 \mathrm{~m} \mathrm{~s}^{-1}$. After the transition, the power had large SNR, $20-40 \mathrm{~dB}$, the values of $v_{\mathrm{LOS}}$ were moderate, $\sim 100 \mathrm{~m} \mathrm{~s}^{-1}$, and the spectral widths decreased to trough-like values, $<60 \mathrm{~m} \mathrm{~s}^{-1}$. What caused this step-like change in the character of the ionospheric scatter?

The velocity was much greater during the AWFC, implying a larger growth rate for gradient drift waves $(\gamma \propto$ $v . \nabla n_{e} / n_{e}$ ), yet the backscatter power increased at the end of the main part of the event. Perhaps the growth rate, $\gamma$, increased at the end of the AWFC because ion-neutral friction reduced the electron density, $n_{e}$ (the denominator), throughout the event. However, this is not satisfactory because ionneutral friction must have reduced the electron density early in the life time of the AWFC, and certainly not in a step-like manner at its end. Freeman et al. (1992) also did not identify a satisfactory explanation for $\sim 10 \mathrm{~dB}$ weaker backscatter powers observed during SARAS.

Simulations by André et al. $(1999,2000)$ suggest that SuperDARN observations of large dayside spectral widths are associated with enhanced Pc1-2 wave activity. Broad-band ULF wave activity will impart a spread of velocities to the ionospheric irregularities. Do the corresponding echoes sum incoherently during the integration time, thereby reducing the SNR? Here we speculate that the reduced backscatter power during our AWFC was caused by an active generator of ULF wave activity increasing the incoherent averaging. The spectral widths decreased in a step-like manner at the end of the AWFC because the ULF wave activity switched off.

These ideas require further quantitative analysis. For example, we might expect the backscatter power to decrease with increasing spectral width for a fixed value of $v_{\text {LOS }}$ (irregularity growth rate). Conversely, for a fixed spectral width (incoherent averaging), the backscatter power will increase with increasing $v_{\text {LOS }}$ (irregularity growth rate). Note that Fig. 3 shows an example of the backscatter power increasing with $v_{\mathrm{LOS}}$ in the trough-like scatter at 11:48 UT.

An initial analysis of MQI magnetograms recorded during our AWFC confirms that large spectral widths were coincident with bursts of broad-band ULF wave activity. Many different kinds of ULF waves were actually observed, the analysis of which is beyond the scope of this paper. However, they may provide important clues about the behaviour of magnetospheric drivers and field-aligned currents coupling to the ionosphere. The AWFC linkage with the auroral electrojet, the westward travelling surge, and associated NS Sunaligned arcs need further investigation. In particular, streamers or NS Sun-aligned arcs which peel off the auroral oval and extend to the latitude of the main ionospheric trough will be investigated further using other AWFC events detected with TIGER. It is interesting to note that reported propagation speeds of NS Sun-aligned arcs (Solovyev et al., 1999) and Ps6 pulsations (Saito, 1978) are both comparable to the westward drift speeds measured during our AWFC. 
The distinction between prompt and longer-lasting penetration of electric fields to mid-latitudes was discussed by Fejer et al. (1993, 1997), Parkinson et al. (2001a), and many others. The strongest prompt penetration fields are radial (poleward) electric fields driving westward drifts in the evening sector (Wand and Evans, 1981). These fields decrease in amplitude with decreasing latitude (Heelis and Coley, 1992). Impulsive penetration fields have been observed at mid-latitudes (Parkinson et al., 2001b). Hitherto, no observations have shown they manifest in narrow channels. Moreover, the occurrence of prompt penetration fields is slightly broader in MLT than PJ/SAIDs, which are thought to concentrate in the 18:00-03:00 MLT sector. However, prompt penetration fields must also be associated with a weaker radial polarisation of ion and electron distributions in the outer plasmasphere, forming under conditions similar to those which might otherwise produce a PJ/SAID. It is reasonable to question whether there is an important connection between the two phenomena.

A digital ionosonde was measuring the apparent bulk motion of the ionosphere above Bundoora $\left(145.1^{\circ} \mathrm{E}, 37.7^{\circ} \mathrm{S}\right.$, geographic; $-49^{\circ} \Lambda$ ) during 27 February. It is well known that the mid-latitude ionosphere is co-rotational to first order, but it also slowly circulates $\left(\sim 50 \mathrm{~m} \mathrm{~s}^{-1}\right)$ under the influence of the ionospheric dynamo, and the penetration of magnetospheric electric fields to low latitudes. As expected, the drifts above Bundoora were $\sim 40 \mathrm{~m} \mathrm{~s}^{-1}$ towards the west, but there were no obvious changes coincident with Substorms 1 or 2 . If AWFCs occurred during both these substorms, they were part of the process of shielding the mid-latitude ionosphere from changes in the high-latitude magnetospheric convection (Southwood, 1977; Southwood and Wolf, 1978).

It follows that direct penetration of electric fields to low latitudes might be stronger if no PJ/SAID occurs during a substorm. However, the energy driving a PJ/SAID must be largely dissipated by Joule heating of the underlying thermosphere. This heating must modify the thermospheric winds which propagate to lower latitudes. Models show how impulsive increases in Joule heating confined to narrow channels will be very efficient sources of atmospheric gravity waves (Hocke and Schlegal, 1996). Despite shielding effects, we might expect the mid-latitude thermosphere and ionosphere to respond indirectly to PJ/SAIDs on time scales of $\sim 1 \mathrm{~h}$ and more. These ideas need testing using observations and models.

How many substorms are accompanied by an AWFC or PJ/SAID, and under what conditions? Why are some substorms accompanied by PJ/SAIDs, but not others? Are AWFC the same as SARAS, and are both phenomena a weaker kind of PJ/SAID? How does the response of the midlatitude ionosphere change when there is a PJ/SAID? Ideally, in the future, PJ/SAIDs should be studied using an extended network of adjacent SuperDARN radars deployed at latitudes comparable to, and even equatorward of, TIGER $\left(-57^{\circ} \Lambda\right)$. During very disturbed conditions $\left(K_{p}>5\right)$, deep, broad main ionospheric troughs are often observed using ionosonde and TEC measurements made at Hobart $\left(-54^{\circ} \Lambda\right)$. This means that significant subauroral processes are presently not accessible to the SuperDARN radars, including TIGER.

More case studies need to be analysed because every event will be observed with varying coverage in the radar FOV, and with more or less favourable satellite conjunctions. Moreover, the underlying physical processes may vary from event to event. There also needs to be more work relating ionospheric observations of substorms to geosynchronous and magnetotail dynamics measured using spacecraft including LAN-L, GEOTAIL, and CLUSTER II. Models of PJ/SAID formation and decay will also need to be reconciled with complex observations like those presented here.

Acknowledgements. This work was supported by the Australian Research Council, the Australian Antarctic Science Advisory Committee, the UK's Natural Environment Research Council, Australian Antarctic Division, DSTO Salisbury, the Ian Potter Foundation, RLM Systems Pty. Ltd, and the State Government of Tasmania. We thank A. S. Rodger of the British Antarctic Survey for insightful discussions. We thank R. Lepping and A. Szabo of Goddard Space Flight Center (GSFC), and A. Lazarus of the Massachusetts Institute of Technology, for providing access to IMP 8 magnetic field and solar-wind data, respectively. Similarly, we thank R. Lepping and K. Ogilvie of GSFC for providing access to Wind magnetic field and solar-wind data. We also thank Simon Wing of the John Hopkins University Applied Physics Laboratory for making DMSP SS J/4 dynamic spectra available over the internet. The distribution of the DMSP ion flow data used in this study were supported by NASA under grant NAG5-9297. Finally, we thank the numerous people who contributed to the operation and maintenance of TIGER.

Topical Editor G. Chanteur thanks M. Roth and T. Karlsson for their help in evaluating this paper.

\section{References}

Anderson, P. C., Heelis, R. A., and Hanson, W. B.: The ionospheric signatures of rapid subauroral ion drifts, J. Geophys. Res., 96, 5785-5792, 1991.

Anderson, P. C., Hanson, W. B., Heelis, R. A., Craven, J. D., Baker, D. N., and Frank, L. A.: A proposed production model of rapid subauroral ion drifts and their relationship to substorm evolution, J. Geophys. Res., 98, 6069-6078, 1993.

André, R., Pinnock, M., and Rodger, A. S.: On the SuperDARN autocorrelation function observed in the ionospheric cusp, Geophys. Res. Lett., 26, 3353-3356, 1999.

André, R., Pinnock, M., and Rodger, A. S.: Identification of the low-altitude cusp by Super Dual Auroral Radar Network radars: A physical explanation for the empirically derived signature, J. Geophys. Res., 105, 27 081-27 093, 2000.

Axford, W. I.: Magnetospheric convection, Rev. Geophys. Space Phys., 7, 421-459, 1969.

Baker, K. B. and Wing, S.: A new magnetic coordinate system for conjugate studies of high latitudes, J. Geophys. Res., 94, 9139 9143, 1989.

Baker, K. B., et. al.: HF radar signatures of the cusp and low-latitude boundary layer, J. Geophys. Res., 100, 7671-7695, 1995.

Cole, K. D.: Joule heating of the upper atmosphere, Aust. J. Phys., $15,223-235,1962$. 
De Keyser, J., Roth, M., and Lemaire, J.: The magnetospheric driver of subauroral ion drifts, Geophys. Res. Lett., 25, 1625-1628, 1998.

De Keyser, J.: Formation and evolution of subauroral ion drifts in the course of a substorm, J. Geophys. Res., 104, 12 339-12 349, 1999.

$\mathrm{Du}$, J. and Stening, R. J.: Simulating the ionospheric dynamo-I. Simulation model and flux tube integrated conductivities, J. Atmos. Solar-Terr. Phys., 61, 913-923, 1999.

Dudeney, J. R. and Rodger, A. S.: Ionospheric signature of plasma sheet thinning prior to a substorm, Planet. Space. Sci., 36, 12851293, 1988

Dyson, P. L. and Devlin, J. C.: The Tasman International Geospace Environment Radar, The Physicist (The Australian Institute of Physics), 37, 48-53, March/April, 2000.

Evans, L. C. and Stone, E. C.: Electron polar cap and the boundary of open geomagnetic field lines, J. Geophys. Res., 77, 5580 5584, 1972.

Fejer, B. G.: F-region plasma drifts over Arecibo: solar cycle, seasonal, and magnetic activity effects, J. Geophys. Res., 98, 13645-13 652, 1993.

Fejer, B. G.: The electrodynamics of the low-latitude ionosphere: recent results and future challenges, J. Atmos. Solar-Terr. Phys., 59, 1465-1482, 1997.

Foster, J. C., Buonsanto, M. J., Mendillo, M., Nottingham, D., Rich, F. J., and Denig, W.: Coordinated stable auroral red arc observations: relationship to plasma convection, J. Geophys. Res., 99, 11 429-11 439, 1994.

Fox, N. J., Cowley, S. W. H., Davda, V. N., et al.: A multipoint study of a substorm occurring on 7 December, 1992, and its theoretical implications, Ann. Geophysicae, 17, 1369-1384, 1999.

Freeman, M. P., Ruohoniemi, J. M., and Greenwald, R. A.: The determination of time-stationary 2-D convection patterns with single station radars, J. Geophys. Res., 96, 15 735-15 749, 1991.

Freeman, M. P., Southwood, D. J., Lester, M., Yeoman, T. K., and Reeves, G. D.: Substorm-associated radar auroral surges, J. Geophys. Res., 97, 12 173-12 185, 1992.

Galperin, Y. I., Ponomarev, V. N., and Zosimova, A. G.: Direct measurements of ion drift velocity in the upper ionosphere during a magnetic storm, 2. Results of measurements during the November 3, 1967, magnetic storm, Cosmic Res (Russian), 11, 283292,1973

Galperin, Y. I., Khalipov, V. L., and Filippov, V. M.: Signature of rapid subauroral ion drifts in the high-latitude ionosphere structure, Ann. Geophysicae, 4, 145-154, 1986.

Galperin, Y. I.: Polarization jet: Characteristics and a model, J. Geophys. Res., submitted, 2002.

Greenwald, R. A., Baker, K. B., Hutchins, R. A., and Hanuise, C.: An HF phased-array radar for studying small-scale structure in the high-latitude ionosphere, Radio Sci., 20, 63-79, 1985.

Greenwald, R. A., et. al.: DARN/SuperDARN: A global view of the dynamics of high-latitude convection, Space Sci. Rev., 71, 761-796, 1995.

Hanuise, C., Villain, J. P., Gresillon, D., Cabrit, B., Greenwald, R. A., and Baker, K. B.: Interpretation of HF radar ionospheric Doppler spectra by collective wave scattering theory, Ann. Geophysicae, 11, 29-39, 1993.

Hardy, D. A., et al.: Precipitating electron and ion detectors (SSJ/4) for the block 5D/flights 6-10 DMSP satellites: Calibration and data presentation, Rep. AFGL-TR-84-0317, Air Force Geophys. Lab., Hanscom Air Force Base, Mass., 1984

Heelis, R. A. and Coley, W. R.: East-west ion drifts at mid-latitudes observed by Dynamics Explorer 2, J. Geophys. Res., 97, 1946119469, 1992.

Heelis R. A., Bailey, G. J., Sellek, R., Moffett, R. J., and Jenkins, B.: Field-aligned drifts in subauroral ion drift events, J. Geophys. Res., 98, 21 493-21 499, 1993.

Henderson, M. G., Reeves, G. D., Belian, R. D., and Murphree, J. S.: Observations of magnetospheric substorms occurring with no apparent solar wind/IMF trigger, J. Geophys. Res., 101, 10773 $10791,1996$.

Hocke, K. and Schlegel, K.: A review of atmospheric gravity waves and travelling ionospheric disturbances: 1982-1995, Ann. Geophysicae, 14, 917-940, 1996.

Huang, C-S., Foster, J. C., and Holt, J. M.: Westward plasma drift in the midlatitude ionospheric F-region in the midnight-dawn sector, J. Geophys. Res., 106, 30 349-30 362, 2001.

Jayachandran, P. T., St.-Maurice, J.-P., MacDougall, J. W., and Moorcroft, D. R.: HF Detection of slow long-lived E-region plasma structures, J. Geophys. Res., 105, 2425-2442, 2000.

Jones, D. G., Walker I. K., and Kersley, L.: Structure of the poleward wall of the trough and the inclination of the geomagnetic field above the EISCAT radar, Ann. Geophysicae, 15, 740-746, 1997.

Karlsson, T., Marklund, G. T., and Blomberg, L. G.: Subauroral electric fields observed by the Freja satellite: A statistical study, J. Geophys. Res., 103, 4327-4341, 1998.

Kelley, M. C., Vickrey, J. F., Carlson, C. W., and Torbert, R.: On the origin and spatial extent of high-latitude F-region irregularities, J. Geophys. Res., 87, 4469-4475, 1982.

Kelley, M. C.: The Earth's ionosphere - Plasma physics and electrodynamics, Academic Press, San Diego, California, 1989.

Kivelson, M. G. and Russell, C. T. (Eds.): Introduction to space physics, Cambridge Univ. Press, Cambridge, U.K., 1995.

Lewis, R. V., Williams, P. J. S., Jones, G. O. L., Opgenoorth, H. J., and Persson, M. A. L.: The electrodynamics of a drifting auroral arc, Ann. Geophysicae, 12, 478-480, 1994.

Lui, A. T. Y. and Murphree, J. S.: A substorm model with onset location tied to an auroral arc, Geophys. Res. Lett., 25, 12691272, 1998.

McPherron, R. L.: Growth phase of magnetospheric substorms, J. Geophys. Res., 75, 5592-5599, 1970.

Newell, P. T. and Meng, C.-I.: Low altitude observations of dispersionless substorm injection fronts, J. Geophys. Res., 92, 10063 $10072,1987$.

Newell, P. T., Feldstein, Y. I., Galperin, Y. I., and Meng,C.-I.: Morphology of nightside precipitation, J. Geophys. Res., 101, 10737-10 748, 1996

Papitashvili, V. O. and Rich, F. J.: High-latitude ionospheric convection models derived from Defense Meteorological Satellite Program ion drift observations and parameterized by the interplanetary magnetic field strength and direction, J. Geophys. Res., 107, in press, 2002.

Parkinson, M. L., Polglase, R., Fejer, B. G., Scherliess, L., Dyson, P L., and Ujmaia, S. M.: Seasonal and magnetic activity variations of ionospheric electric fields above the southern mid-latitude station, Bundoora, Australia, Ann. Geophysicae, 19, 521-532, 2001a.

Parkinson, M. L., Polglase, R., Dyson, P. L., Fejer, B. G., Scherliess, L., and Ujmaia, S. M.: Electric field measurements at a southern mid-latitude station obtained using an HF digital ionosonde, Adv. Space Res., 27, 1253-1258, 2001b.

Parkinson, M. L., Dyson, P. L., Pinnock, M., Devlin, J. C., Hairston, M. R., Yizengaw, E., and Wilkinson, P. J.: Signatures of the 
midnight open-closed magnetic field-line boundary during balanced dayside and nightside reconnection, Ann. Geophysicae, 20, 1617-1630, 2002.

Ponomarenko, P. V., Waters, C. L., Sciffer, M. D., Fraser, B. J., and Samson, J. C.: Spatial structure of ULF waves: Comparisons of magnetometer and Super Dual Auroral Radar Network data, J. Geophys. Res., 106, 10 509-10 517, 2001.

Providakes, J. F., Kelley, M. C., and Swartz, W. E.: Radar and optical measurements of ionospheric processes associated with intense subauroral electric fields, J. Geophys. Res., 94, 5350-5366, 1989.

Quegan, S., Bailey, G. J., Moffett, R. J., Heelis, R. A., FullerRowell, T. J., Rees, D., and Spiro, R. W.: A theoretical study of the distribution of ionization in the high-latitude ionosphere and the plasmasphere: first results on the mid-latitude trough and the light-ion trough, J. Atmos. Terr. Phys., 44, 619-640, 1982.

Rich, F. J., Burke, W. J., Kelley, M. C., and Smiddy, M.: Observations of field-aligned currents in association with strong convection electric fields at subauroral latitudes, J. Geophys. Res., 85, 2335-2340, 1980.

Rodger, A. S., Brace, L. H., Hoegy, W. R., and Winningham, J. D.: The poleward edge of the mid-latitude trough-its formation, orientation and dynamics, J. Atmos. Terr. Phys., 48, 715-728, 1986.

Rodger, A. S., Moffett, R. J., and Quegan, S.: The role of ion drift in the formation of ionisation troughs in the mid- and high-latitude ionosphere - a review, J. Atmos. Terr. Phys., 54, 1-30, 1992.

Ruohoniemi, J. M., Greenwald, R. A., Villain, J.-P., Baker, K. B., Newell, P. T., and Meng, C.-I.: Coherent HF radar backscatter from small-scale irregularities in the dusk sector of the subauroral ionosphere, J. Geophys. Res., 93, 12 871-12 882, 1988.

Ruohoniemi, J. M., Greenwald, R. A., Baker, K. B., Villain, J.-P., Hanuise, C., and Kelly, J.: Mapping high-latitude plasma convection with coherent HF radars, J. Geophys. Res., 94, $13463-$ $13477,1989$.

Saito, T.: Geomagnetic pulsations, Space Sci. Rev., 10, 319-412, 1969.

Saito, T.: Long-period irregular magnetic pulsations, Pi3, Space Sci. Rev., 21, 427-467, 1978

Samson, J. C., Cogger, L. L., and Pao, Q.: Observations of field line resonances, auroral arcs, and auroral vortex structures, J. Geophys. Res., 101, 17 373-17 383, 1996.

Sánchez, E. R., Ruohoniemi, J. M., Meng, C.-I., and FriisChristensen, E.: Toward an observational synthesis of substorm models: Precipitation regions and high-latitude convection reversals observed in the nightside auroral oval by DMSP satellites and HF radars, J. Geophys. Res., 101, 19 801-19837, 1996.
Schunk, R. W., Banks, P. M., and Raitt, W. J.: Effects of electric fields and other processes upon the nightime high-latitude F-layer, J. Geophys. Res., 80, 3121-3130, 1975.

Sellek, R., Bailey, G. J., Moffett, R. J., Heelis, R. A., and Anderson, P. C.: Effects of large zonal plasma drifts on the subauroral ionosphere, J. Atmos. Terr. Phys., 53, 557-565, 1991.

Smiddy, M., Kelley, M. C., Burke, W., Rich, F., Sagalyn, R., Shuman, B., Hays, R., and Lai, S.: Intense poleward directed electric fields near the ionospheric projection of the plasmapause, Geophys. Res. Lett., 4, 543-546, 1977.

Sojka, J. J. and Schunk, R. W.: Theoretical study of the seasonal behavior of the global ionosphere at solar maximum, J. Geophys. Res., 94, 6739-6749, 1989.

Solovyev, S. I., Baishev, D. G., Barkova, E. S., Engebretson, M. J., Posch, J. L., Hughes, W. J., Yumoto, K., and Pilipenko, V. A.: Structure of disturbances in the dayside and nightside ionosphere during periods of negative interplanetary magnetic field $B_{z}, \mathrm{~J}$. Geophys. Res., 104, 28 019-28 039, 1999.

Southwood, D. J.: The role of hot plasma in magnetospheric convection, J. Geophys. Res., 82, 5512-5520, 1977.

Southwood, D. J. and Wolf, R. A.: An assessment of the role of precipitation in magnetospheric convection, J. Geophys. Res., 83, 5227-5232, 1978 .

Spiro, R. W., Heelis, R. A., and Hanson, W. B.: Rapid subauroral ion drifts observed by Atmospheric Explorer C, Geophys. Res. Lett., 6, 660-663, 1979.

Starkov, G. V.: Mathematical model of the auroral boundaries, Geomag. Aeronomy, 34, 331-336, 1994.

Tsyganenko, N. A. and Stern, D. P.: Modeling the global magnetic field of the large-scale Birkeland current systems, J. Geophys. Res., 101, 27 187-27 198, 1996.

Uspensky, M., Eglitis, P., Opgenoorth, H., Starkov, G., Pulkkinen, T., and Pellinen, R.: On auroral dynamics observed by HF radar: 1. Equatorward edge of the afternoon-evening diffuse luminosity belt, Ann. Geophysicae, 18, 1560-1575, 2001.

Vampola, A. L.: Access of solar electrons to closed field lines, J. Geophys. Res., 76, 36-43, 1971.

Wand, R. H. and Evans, J. V.: The penetration of convection electric fields to the latitude of Millstone Hill $\left(\Lambda=56^{\circ}\right)$, J. Geophys. Res., 86, 5809-5814, 1981.

Watanabe, M., et al.: Localized activation of the distant tail neutral line just prior to substorm onsets, J. Geophys. Res., 103, $17651-$ $17669,1998$.

Yeh, H.-C., Foster, J. C., Rich, F. J., and Swider, W.: Storm time electric field penetration observed at mid-latitude, J. Geophys. Res., 96, 5707-5721, 1991. 